University of Louisville

ThinkIR: The University of Louisville's Institutional Repository

Electronic Theses and Dissertations

2-1979

\title{
Analysis of structures subjected to dynamic loading.
}

Jose Enrique Carrasco 1950-

University of Louisville

Follow this and additional works at: https://ir.library.louisville.edu/etd

\section{Recommended Citation}

Carrasco, Jose Enrique 1950-, "Analysis of structures subjected to dynamic loading." (1979). Electronic Theses and Dissertations. Paper 213.

https://doi.org/10.18297/etd/213

This Master's Thesis is brought to you for free and open access by ThinkIR: The University of Louisville's Institutional Repository. It has been accepted for inclusion in Electronic Theses and Dissertations by an authorized administrator of ThinkIR: The University of Louisville's Institutional Repository. This title appears here courtesy of the author, who has retained all other copyrights. For more information, please contact thinkir@louisville.edu. 
ANALYSIS OF STRUCTURES

SUB'JECTED TO DYNAMIC LOADING

By

Jose Enrique Carrasco

B.S., University of L'ouisvil1e, 1977

\author{
A Thesis \\ Submitted to the Faculty of the \\ University of Louisville \\ Speed Scientific School
}

as Partial Fulfillment of the Requirements

for the Professional Degree

MASTER OF ENGINEERING

Department of Civil Engineering

February 1979 
ANALYSIS OF STRUCTURES

SUBJECTED TO DYNAMIC LOADING

Submitted by.

Jøse Enrique Carrasco

A Thesis Approved on

$\frac{\text { Aebrary } 20,1979}{\text { Date }}$

by the Following Reading and Examination Committee:

Thes is Director, Mario M. Paz

Edmond Mit7er

Michael A. Cassaro

Gilbert A. Rabirez 


\section{ABSTRACT}

The objective of this thesis is to develop computer programs for the dynamic analysis of structures. For a shear building two computer programs were developed: (1) Dynamic Analysis of a Shear Building within the Elastic Range and (2) the Dynamic Analysis of a Shear Building with Elasto-Plastic Behavior.

Parallel to this computer work a study was performed to investigate the error due to static condensation applied to dynamic problems. In the development of computer programs the stiffness method and the consistent mass matrix were used; and viscous damping was assumed. 
ACKNOWLEDGEMENTS ......................... i i

ABSTRACT ........................... iv

TABLE OF CONTENTS .................. v

NOMENCLATURE ............................... vii

LIST OF FIGURES ........................ ix

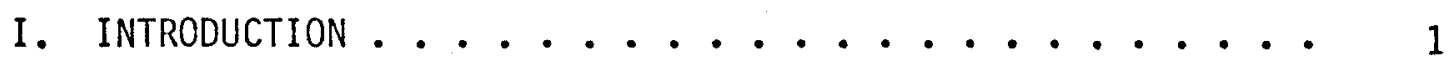

II. FREE VIBRATION OF A SHEAR BUILDING .......... 2

A. Concept of Shear Building.......... 2

B. Free Vibration ......... 2

C. Orthogonality Property of Normal Modes ..... 6

D. Numerical Example ........... 8

E. Subroutine Jacobi ............ 13

III. FORCED VIBRATION OF SHEAR BUILDING . . . . . . 15

A. Modal Superposition Method .......... 15

B. Numerical Example . . . . . . . . . 17

C. Response of a Shear-Building to Ground Motion . . 19

D. Subroutine Modal ............. 22

IV. DAMPED MOTION OF SHEAR BUILDING . . . . . . . . 24

A. Equation of Motion for Damped Systems . . . 25

B. Conditions to Uncouple Equations in Damped Systems. 28

C. Subroutine Damp ........... 32

D. Seismic Response of an Elastic Shear Building . . 32

E. Computer Program \#1 ........... 35

F. Computer Program \#2 ........... 43

V. ERROR INVESTIGATION DUE TO STATIC CONDENSATION . . . . 49

A. Static Condensation ........... 49

B. Static Condensation Applied to Dynamic Problems . . 52

C. Numerical Example ........... 54

D. Computer Program for Investigation of Error.... 59

E. Computer Program \#3......... 60 
Page

VI. ANALYSIS OF NONLINEAR STRUCTURES RESPONSE . . . . . . 68

A. Incremental Equation of Equilibrium . . . . . . 68

B. Step-by-Step Integration ............ 72

C. Incremental Equation of Motion . . . . . . . 76

D. The Wilson- $\theta$ Method . • • • • • • • • • • • 77

E. Algorithm for Step-by-Step Solution of a Linear

System, Using the Wilson- $\theta$ Integration Method . . 81

F. Subroutine Step . . . . . . . . . . . . 84

G. Program \#4 ................. . 84

H. Illustrative Example .............. 87

I. Program Listing . . . . . . . . . . . 89

BIBLIOGRAPHY . . • . . . . . . . . . . . . . . 9 98

VITA . . . . . . . . . . . . . . . . . 99 
NOMENCLATURE

Roman Alphabet

\begin{tabular}{|c|c|}
\hline$P_{i}(t)$ & $\begin{array}{l}\text { the normal force at function of time acting on ith level } \\
\text { the maximum response from the spectrum at ith }\end{array}$ \\
\hline & 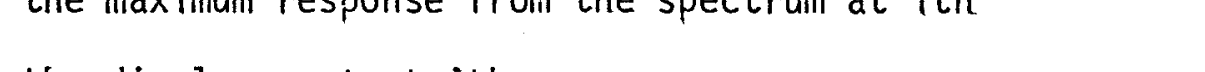 \\
\hline$x_{i}$ & the displacement at ith \\
\hline$\dot{x}_{i}$ & the velocity at ith \\
\hline$\ddot{x}_{i}$ & the acceleration at ith \\
\hline g & the constant of gravity \\
\hline$c_{i}$ & the damping at ith \\
\hline $\mathrm{K}_{\mathbf{i}}$ & the stiffness in column $i$ in the lower floor level \\
\hline$F_{i}(t)$ & the forcing function at ith in function of time \\
\hline$m_{i}$ & mass concentrated at level $i$ \\
\hline$[\mathrm{C}]$ & the damping matrix \\
\hline [K] & the stiffness matrix \\
\hline$\{\mathrm{F}\}$ & the forcing vector \\
\hline$\{X\}$ & the displacement vector \\
\hline$\{\AA\}$ & the velocity vector \\
\hline$\{\ddot{X}\}$ & the acceleration vector \\
\hline$a_{i}$ & amplitude of motion of ith coordinate \\
\hline$a_{i j}$ & $\begin{array}{l}\text { amplitude of the mode shape at coordinate } i \text { mode } n \\
\text { (before normalization) }\end{array}$ \\
\hline [1] & unit matrix \\
\hline$z_{i}(t)$ & factor which will uncouple a set of coupled equations \\
\hline$[\mathrm{T}]$ & transformation matrix \\
\hline$\left\{x_{p}\right\}$ & $\begin{array}{l}\text { the vector corresponding to the } p \text { degrees of freedom to } \\
\text { be reduced }\end{array}$ \\
\hline
\end{tabular}




\section{INTRODUCTION}

Almost any type of structure may be subjected to dynamic loading in one form or another during its existence. From the analytical point of view, it is convenient to divide the dynamic loading condition into two basic categories; periodic and nonperiodic. Periodic loadings are repetitive loads which exhibit the same time variation successively for

a large number of cycles. A typical case for periodic motion is rotating machinary in a building. On the other hand nonperiodic loadings may be either short-duration, impulsive loadings or long duration, general forms of loads. A typical nonperiodic motion is a nuclear blast or an earthquake excitation.

In recent years considerable emphasis has been given to the problems of blast and earthquakes. The earthquake problem is rather old, but most of the knowledge on this subject was developed in the last two decades. The blast problem is rather new and information is made available mostly through publications of the Army Corps of Engineers, Department of Defense Agency, and other federal agencies. It is very important to mention the fact that in the last decade the rapid expansion in number and size of nuclear power plants in regions close to large populated centers requires very careful structural consideration.

As an effort toward developing better techniques in the field of structural dynamics, the main objective of this thesis is to develop computer programs for structures modeled as a shear building subjected to dynamic loading conditions and the investigation of error, due to static condensation. 


\section{FREE VIBRATION OF A SHEAR BUILDING}

A. Concept of a Shear Building. A shear building may be defined as a structure in which there is no rotation of a horizontal section at the level of the floors. In this respect, the deflected building will have many of the features of a cantilever beam that is deflected by shear forces only; hence, the name shear building. To accomplish such deflection in a building, it must be assumed that (1) the total mass of the structure is concentrated at the levels of the floors; (2) the girders on the floors are infinitely rigid as compared to the columns; and (3) the deformation of the structure is independent of the axial forces present in the columns.

B. Free Vibration. When free vibration is under consideration, the structure is not subjected to any external excitation (force or support motion) and its motion is governed only by the initial conditions. There are occasionally circumstances for which it is necessary to determine the motion of the structure under conditions of free vibration, but this is seldom the case. Nevertheless, the analysis of the structure in free motion provides the most important dynamic properties of the structure which are the natural frequencies and the corresponding normal modes.

Figure 1(a) shows the possible displacements of a two-story shear building and figure 1 (b) shows the two possible modes of vibration. 


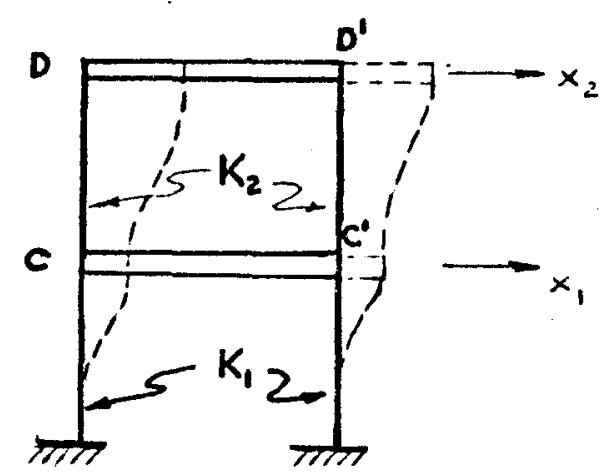

FIGURE 1(a) - Possible Displacements of a Two Story-Shear Building
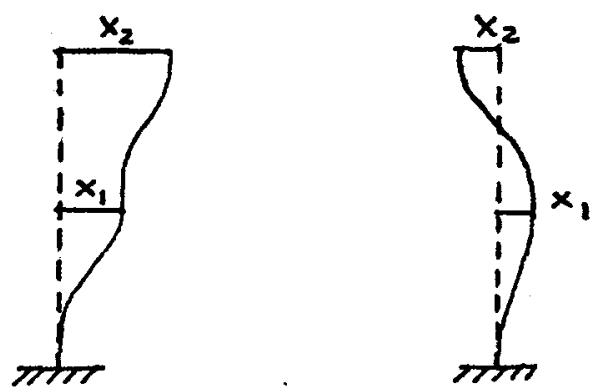

FIGURE 1(b) - First and Second Mode of Vibration

Any displacement $x_{1}$ of member $C^{-} C^{\prime}$ is resisted by the restoring forces of the columns. If $K_{1}$ is the stiffness of the first story then the force on $C^{-} C^{\prime}$ will be $-K_{1} x_{1}$. If $K_{2}$ is the stiffness of the second story then the forces on $C-C^{\prime}$ and $D-D^{\prime}$ are $-K_{2}\left(x_{1}-x_{2}\right)$ and $K_{2}\left(x_{2}-x_{1}\right)$ respective1y. The equations of motion are then obtained from the corresponding free body diagram as is shown in Figure 2.

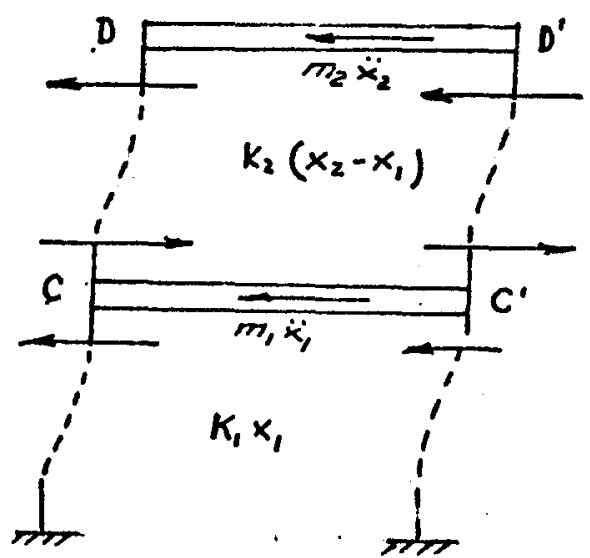

FIGURE 2 - Free Body Diagram of a Two-Story Shear Building 
Hence, equating to zero the sum of forces in $x$ direction for bodies $C^{-} C^{\prime}$ and $D-D$ ' results in

$$
\begin{gathered}
m_{1} \ddot{x}_{1}+k_{1} x_{1}-k_{2}\left(x_{2}-x_{1}\right)=0 \\
m_{2} \ddot{x}_{2}+k_{2}\left(x_{2}-x_{1}\right)=0
\end{gathered}
$$

and rearranging these equations gives

$$
\begin{gathered}
m_{1} \ddot{x}_{1}+\left(k_{1}+k_{2}\right) x_{1}-k_{2} x_{2}=0 \\
m_{2} \ddot{x}_{2}+k_{2} x_{2}-k_{2} x_{1}=0
\end{gathered}
$$

where $\ddot{x}_{1}, \ddot{x}_{2}$ are the accelerations and $x_{1}, x_{2}$ represent the displacements. Equations (3) and (4) may be written as

$$
\left[\begin{array}{ll}
m_{1} & 0 \\
0 & m_{2}
\end{array}\right]\left[\begin{array}{l}
\ddot{x}_{1} \\
\ddot{x}_{2}
\end{array}\right]+\left[\begin{array}{cc}
k_{1}+k_{2} & -k_{2} \\
-k_{2} & k_{2}
\end{array}\right]\left[\begin{array}{l}
x_{1} \\
x_{2}
\end{array}\right]=\left[\begin{array}{l}
0 \\
0
\end{array}\right] .
$$

or in a condensed form as

$$
[M]\{\ddot{x}\}+[K]\{x\}=\{0\}
$$

in which

$[M]$ is the mass matrix,

$[K]$ is the stiffness matrix,

$\{\ddot{x}\}$ is the acceleration vector, and

$\{x\}$ is the vector displacement. 
The system of equation (5) is linear and homogeneous, and its solution can be expressed as

$$
\begin{aligned}
& x_{1}=a_{1} e^{i \omega t} \\
& x_{2}=a_{2} e^{i \omega t}
\end{aligned}
$$

where $a_{1}$ and $a_{2}$ are constants, and $\omega$ is a parameter to be determined. Substituting (7) into (5) results in

$$
\begin{gathered}
\left\{-m_{1} \omega^{2} a_{1}+\left(K_{1}+K_{2}\right) a_{1}-K_{2} a_{2}\right\} e^{i \omega t}=0 \\
\left\{-m_{2} \omega^{2} a_{2}+K_{2} a_{2}-K_{1} a_{1}\right\} e^{i \omega t}=0
\end{gathered}
$$

which upon simplification gives

$$
\begin{gathered}
\left\{\left(K_{1}+K_{2}\right)-\omega^{2} m_{1}\right\} a_{1}-K_{2} a_{2}=0 \\
-K_{2} a_{1}+\left(K_{2}-\omega^{2} m_{2}\right) a_{2}=0
\end{gathered}
$$

or in matrix form

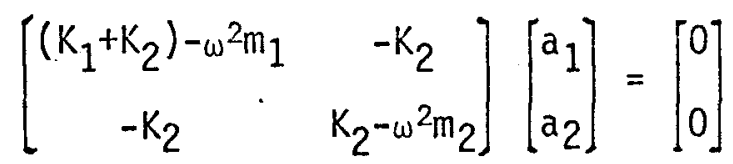

and in condensed notation

$$
\left\{[K]-\omega^{2}[M]\right\}\{a\}=\{0\}
$$


Equation (9) is satisfied for the trivial solution, that is, $a_{1}=a_{2}=0$; however this solution would indicate no motion of the structure and therefore will not satisfy the initial conditions of the problem. In order to find the nontrivial solution for this homogeneous system of equations, the determinant of the coefficient matrix has to be equal to zero, that is

$$
\left|\begin{array}{cc}
\left(k_{1}+k_{2}\right)-m_{1} \omega^{2} & -k_{2} \\
-k_{2} & k_{2}-m_{2} w^{2}
\end{array}\right|=0
$$

The expansion of the determinant results in a quadratic equation in $\omega^{2}$, namely

$$
m_{1} m_{2} \omega^{4}-\left[\left(K_{1}+K_{2}\right) m_{2}+m_{1} K_{2}\right] \omega^{2}+K_{1} K_{2}=0
$$

After the roots of (13), $\omega_{1}$ and $\omega_{2}$ (natural frequencies) are determined and substituting back into equation (11) the relative amplitudes of motion (normal modes) can be found.

\section{Orthogonality Property of the Nomal Modes. This property} constitutes the basis of one of the most attractive methods for solving dynamic problems of multi-degree-of-freedom systems. For a system of two-degree-of-freedom equations (11) may be written as

$$
\begin{gathered}
\left(k_{1}+k_{2}\right) a_{1}-k_{2} a_{2}=m_{1} \omega^{2} a_{1} \\
-k_{2} a_{1}+k_{2} a_{2}=m_{2} \omega^{2} a_{2}
\end{gathered}
$$


The normal modes may then be considered as the static deflections resulting from the forces on the right of (14) for any of the two modes. For the following two systems of loading and corresponding displacement System I:

$$
\begin{array}{rrc}
\text { Forces: } & \omega_{1}^{2} a_{11} m_{1}, \omega_{1}^{2} a_{21} m_{2} \\
\text { Displacements: } & a_{12} & a_{22}
\end{array}
$$

System II:

$$
\begin{array}{rcc}
\text { Forces: } & \omega_{2}^{2} a_{12} m_{1}, w_{2}^{2} a_{22} m_{2} \\
\text { Displacements: } & a_{11} & a_{21}
\end{array}
$$

The application of Betti's theorem yields:

$$
\omega_{1}^{2} m_{1} a_{11} a_{12}+\omega_{1}^{2} m_{2} a_{21} a_{22}=\omega_{2}^{2} m_{1} a_{12} a_{11}+\omega_{2}^{2} m_{2} a_{22} a_{21}
$$

or

$$
\left(\omega_{1}^{2}-\omega_{2}^{2}\right)\left(m_{1} a_{11} a_{12}+m_{2} a_{21} a_{22}\right)=0
$$

If the natural frequences are different $\left(\omega_{1} \neq \omega_{2}\right)$, it follows from (16) that

$$
m_{1} a_{11} a_{12}+m_{2 a_{21}} a_{22}=0
$$

Equation (17) is the orthogonality relation between the normal modes of a two-degree-of-freedom system. The modes are conveniently normalized to satisfy the following relation: 


$$
\begin{gathered}
8 \\
m_{1} \phi_{11}^{2}+m_{2} \phi_{21}^{2}=1 \\
m_{1} \phi_{12}^{2}+m_{2 \phi}^{2}=1
\end{gathered}
$$

where

$$
\begin{array}{ll}
\phi_{11}=\frac{a_{11}}{\sqrt{m_{1} a_{11}^{2}+m_{2} a_{21}^{2}}} & \phi_{12}=\frac{a_{12}}{\sqrt{m_{1} a_{12}^{2}+m_{2} a_{22}^{2}}} \\
\phi_{21}=\frac{a_{21}}{\sqrt{m_{1} a_{11}^{2}+m_{2} a_{21}}} & \phi_{22}=\frac{a_{22}}{\sqrt{m_{1} a_{12}^{2}+m_{2} a_{22}}}
\end{array}
$$

D. Numerical Example. To illustrate the steps of the procedure for the determination of the natural frequencies and normal modes, consider the two-degrees-of-freedon system shown in Figure 3, in which the initial conditions are the following: $x_{01}=0, x_{02}=1.0$ in, $\dot{x}_{01}=0$, $\dot{x}_{02}=0$

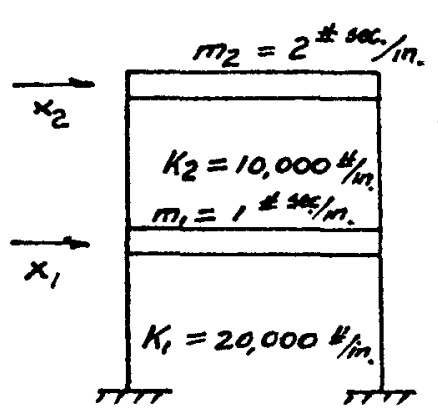

FIGURE 3 - Example of a Two Story Shear Building

Substituting numerical values in (3) and (4) gives

$$
\begin{aligned}
& 1 \ddot{x}_{1}+30,000 x_{1}-10,000 x_{2}=0 \\
& 2 \ddot{x}_{2}-10,000 x_{1}+10,000 x_{2}=0
\end{aligned}
$$


or in matrix notation

$$
\left[\begin{array}{ll}
1 & 0 \\
0 & 2
\end{array}\right]\left[\begin{array}{l}
\ddot{x}_{1} \\
\ddot{x}_{2}
\end{array}\right]+\left[\begin{array}{rr}
30,000 & -10,000 \\
-10,000 & 10,000
\end{array}\right]\left[\begin{array}{l}
x_{1} \\
x_{2}
\end{array}\right]=0
$$

assuminy solution given by (7) results in

$$
\left[\begin{array}{cc}
30,000-\omega^{2} & -10,000 \\
-10,000 & 10,000-2 \omega^{2}
\end{array}\right]\left[\begin{array}{l}
a_{1} \\
a_{2}
\end{array}\right]=\left[\begin{array}{l}
0 \\
0
\end{array}\right]
$$

Then, the characteristic equation is

$$
\left|\begin{array}{cc}
30,000-\omega^{2} & -10,000 \\
-10,000 & 10,000-2 \omega^{2}
\end{array}\right|=0
$$

and in expanded form

$$
\left(\omega^{2}\right)^{2}-35,000 \omega^{2}+\left(100 \times 10^{6}\right)=0
$$

which has the following roots

$$
\begin{aligned}
& \omega_{1}^{2}=31,861.4 \\
& \omega_{2}^{2}=3,138.6
\end{aligned}
$$

Then, the natural frequencies for this structure are 


$$
\begin{aligned}
& \omega_{1}=178.49 \mathrm{rad} / \mathrm{sec} \\
& \omega_{2}=56.02 \mathrm{rad} / \mathrm{sec}
\end{aligned}
$$

Consider the first equation of $(10)$ and substituting the first natural frequency, $\omega_{1}=178.49 \mathrm{rad} / \mathrm{sec}$ results in

$$
-1861.4 a_{11}-10,000 a_{21}=0
$$

A second subindex was introduced in $a_{1}$ and $a_{2}$ to indicate that the value $a_{1}$ has been used in this equation. Since in this case there are two unknowns and only one independent equation it is possible to solve for the relative value of $a_{21}$ and $a_{11}$. This relative value is known as the normal mode or modal shape corresponding to the first frequency. For this example, the first normal mode is

$$
\frac{a_{21}}{a_{11}}=-0.18614
$$

It is customary to describe the normal modes by assigning a unit value to one of the amplitudes; thus, for the first mode setting $a_{11}$ equal to unity

$$
\begin{aligned}
& a_{11}=1.00 \\
& a_{21}=1.263
\end{aligned}
$$


Similarly, substituting the second natural frequency, $\omega_{2}=56.02 \mathrm{rad} / \mathrm{sec}$ into (10), gives the second normal mode as

$$
\begin{aligned}
& a_{12}=1.00 \\
& a_{22}=2.6861
\end{aligned}
$$

The normal modes are conveniently arranged in the column of the modal matrix as

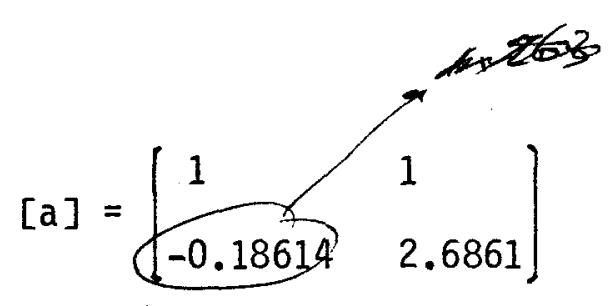

The general solution to the equations of motion for free vibration in terms of constant of integration $A_{1}, A_{2}, A_{3}$ and $A_{4}$ takes the following form:

$$
\begin{aligned}
& x_{1}(t)=a_{11} A_{1} \sin \omega_{1} t+a_{11} A_{2} \cos \omega_{1} t+a_{21} A_{3} \sin \omega_{2} t+a_{12} A_{4} \cos \omega_{2} t \\
& x_{2}(t)=a_{21} A_{1} \sin \omega_{1} t+a_{21} A_{2} \cos \omega_{1} t+a_{22} A_{3} \sin \omega_{2} t+a_{22} A_{4} \cos \omega_{2} t
\end{aligned}
$$

which upon numerical substitution yields

$$
\begin{aligned}
x_{1}(t)= & A_{1} \sin \omega_{1} t+A_{2} \cos \omega_{1} t+A_{3} \sin \omega_{2} t+A_{4} \cos \omega_{2} t \\
x_{2}(t)= & -0.18614 A_{1} \sin \omega_{1} t-0.18614 A_{2} \cos \omega_{1} t+2.086 A_{3} \sin \omega_{2} t \\
& +2.686 A_{4} \cos \omega_{2} t
\end{aligned}
$$


Evaluation of the constants of integration is performed by using the initial conditions which for this example are

$$
x_{01}=0 \quad x_{02}=1.0 \text { in } \quad \dot{x}_{01}=0 \quad \dot{x}_{02}=0
$$

Performing all the necessary algebra and solving for the constants of integration, gives

$$
\begin{array}{ll}
A_{1}=0 & A_{2}=-0.34817 \\
A_{2}=0 & A_{4}=0.34817
\end{array}
$$

Then, the general solution may be expressed as

$$
\begin{aligned}
& x_{1}=-0.34817 \cos 178.5 t+0.34817 \cos 56.02 t \\
& x_{2}=0.0648 \cos 178.5 t+0.9353 \cos 56.02 t
\end{aligned}
$$

and finally the normalized vectors are calculated by using equation (18) as

$$
\begin{aligned}
& \phi_{11}=\frac{1}{\sqrt{1(1)^{2}+2(-0.18614)^{2}}}=0.9670 \\
& \phi_{12}=\frac{1}{\sqrt{1(1)^{2}+2(2.6861)^{2}}}=0.2545 \\
& \phi_{21}=\frac{-0.18614}{\sqrt{1(1)^{2}+2(-0.8614)^{2}}}=-0.18
\end{aligned}
$$




$$
\phi_{22}=0.6838
$$

In matrix form, the normal modes can be represented as

$$
\Phi=\left[\begin{array}{cc}
0.9670 & 0.2545 \\
-0.180 & 0.6838
\end{array}\right]
$$

On free vibration of a shear building the eigenproblem was solved to determine the natural frequencies and normal modes of vibration. For a system of many degrees of freedom, the algebraic and numerical work required for the solution of an eigenproblem became a tedious task. For the purpose of solving an eigenproblem, the Jacobi Method was selected among several numerical methods.

E. Subroutine Jacobi. This subroutine program developed by Professor Wilson is used throughout this thesis to solve the eigenproblem. The description of the symbols utilized in this program are

\begin{tabular}{|c|c|c|}
\hline Variables & Symbol in Thes is & Description \\
\hline$A(I, I)$ & {$[\mathrm{K}]$} & Stiffness matrix \\
\hline$B(I, I)$ & {$[M]$} & Mass matrix \\
\hline$X(I, I)$ & {$[\Phi]$} & Modal matrix \\
\hline $\operatorname{EIGV}(\mathrm{I})$ & $\omega_{1}^{2}$ & Eigenvalues \\
\hline$D(I)$ & & Working Vector \\
\hline N & & Order of matrices $A$ and $B$ \\
\hline RTOL & & $\begin{array}{l}\text { Converge Tolerance (Set to } \\
10 .-12 \text { ) }\end{array}$ \\
\hline NSMAX & & $\begin{array}{l}\text { Maximum number of sweeps } \\
\text { (Set to } 15)\end{array}$ \\
\hline ISPR & & $\begin{array}{l}\text { Index for printing during itera- } \\
\text { tion } 1=\text { Print; } 0=\text { Do not Print }\end{array}$ \\
\hline
\end{tabular}
listed as follows: 
14

And the input data is subjected to the following formats

Formats

$2 \mathrm{I} 10$

$8 \mathrm{~F} 10.4$

$8 \mathrm{~F} 10.4$
Variables

$N$, IFPR

$A(I, J)$ (read by rows)

$B(I, J)$ (read by rows) 
III. FORCED VIBRATION OF SHEAR BUILDINGS

In the preceding chapter, it was shown that the free motion of a dynamic system may be expressed in terms of the normal modes in free vibration. The objective of this chapter is to show that the normal modes may also be used to transform the system of coupled differential equations into a set of uncoupled differential equations in which each equation contains only one dependent variable. Thus, the modal superposition method reduces the problem of finding the response of a multidegree-of-freedom system to the determination of the response of a single degree-of-freedom systems.

A. Modal Superposition Method

Considering the equation of motion for a two story building subjected to forced vibration.

$$
\begin{gathered}
m_{1} \ddot{x}_{1}+\left(k_{1}+k_{2}\right) x_{1}-k_{2} x_{2}=F_{1}(t) \\
m_{2} \ddot{x}_{2}-k_{2} x_{1}+k_{2} x_{2}=F_{2}(t)
\end{gathered}
$$

In seeking the transformation from a coupled system into an uncoupled system of equations in which each equation contains only one unknown, it is necessary to express the solution in terms of the normal modes multiplied by some factors determining the contribution of each mode. Hence, the solution of (19) is assumed to be of the form:

$$
\begin{aligned}
& x_{1}(t)=a_{11} z_{1}(t)+a_{12} z_{2}(t) \\
& x_{2}(t)=a_{21} z_{1}(t)+a_{22} z_{2}(t)
\end{aligned}
$$


Substituting (20) into (19) gives

$$
\begin{gathered}
m_{1} a_{11} z_{1}+\left(k_{1}+k_{2}\right) a_{11} z_{1}-k_{2} a_{21} z_{1}+m_{1} a_{12} \ddot{z}_{2}+\left(k_{1}+k_{2}\right) a_{12} z_{2}-k_{2} a_{11} z_{2}= \\
F_{1}(t)
\end{gathered}
$$

$m_{2} a_{21} \ddot{z}_{1}-k_{2} a_{11} z_{1}+k_{2} a_{21} z_{1}+m_{2} a_{22} \ddot{z}_{2}-k_{2} a_{12} z_{2}+k_{2} a_{22} z_{2}=F_{2}(t)$

To determine the appropriate factors $z_{1}(t)$ and $z_{2}(t)$ which will uncouple (21) it is advantageous to make use of the orthogonality relations to separate the modes. This is accomplished by multiplying the first of the equations (21) by $a_{11}$ and the second by $a_{21}$. The addition of these equations after all the necessary algebra is performed, equation (21) yields:

$$
\left(m_{1} a_{11}^{2}+m_{2} a_{21}^{2}\right) \ddot{z}_{1}+w_{1}^{2}\left(m_{1} a_{11}^{2}+m_{2} a_{21}^{2}\right) z_{1}=a_{11} F_{1}(t)+a_{21} F_{2}(t)
$$

Similarly, multiplying the first of (21) by $a_{12}$ and the second by $a_{22}$, yields

$$
\left(m_{1} a_{12}^{2}+m_{2} a_{22}^{2}\right) \ddot{z}_{2}+w_{2}^{2}\left(m_{1} a_{12}^{2}+m_{2} a_{22}^{2}\right) z_{2}=a_{12} F_{1}(t)+a_{22} F_{2}(t)
$$

Therefore, equations (22) $a$ and (22) b correspond to a single degree-offreedom system which may be written as

$$
\begin{aligned}
& M_{1} \ddot{z}_{1}+k_{1} z_{1}=P_{1}(t) \\
& M_{2} \ddot{z}_{2}+k_{2} z_{2}=P_{2}(t)
\end{aligned}
$$


in which, $M_{1}=m_{1} a_{11}^{2}+m_{2} a_{22}^{2}$ and $M_{2}=m_{1} a_{12}^{2}+m_{2} a_{22}^{2}$ are the modal masses; $K_{1}=\omega_{1}^{2} M_{1}$ and $K_{2}=\omega_{2}^{2} M_{2}$, the modal spring constants and $P_{1}(t)=a_{11} F_{1}(t)+$ $a_{21} F_{2}(t)$ and $P_{2}(t)=a_{12} F_{1}(t)+a_{22} F_{2}(t)$ are the modal forces. When the modal shapes are normalized, equation (23) can be written as

$$
\begin{aligned}
& \ddot{z}_{1}+\omega_{1}^{2} z_{1}=P_{1}(t) \\
& \ddot{z}_{2}+\omega_{2}^{2} z_{2}=P_{2}(t)
\end{aligned}
$$

in which, $P_{1}$ and $P_{2}$ are given by

$$
\begin{aligned}
& P_{1}=\phi_{11} F_{1}(t)+\phi_{21} F_{2}(t) \\
& P_{2}=\phi_{12} F_{1}(t)+\phi_{22} F_{2}(t)
\end{aligned}
$$

The solution of the uncoupled equation (23) or (24) can be found by the application of Duhamel's integral as will be shown in a numerical example. B. Numerical Example

Consider the structure of the numerical example of chapter one shown in Figure 3 with the only difference that, this time the first and the second story are subjected to constant loading applied suddenty at $t=0$; as is shown in Figure 4.

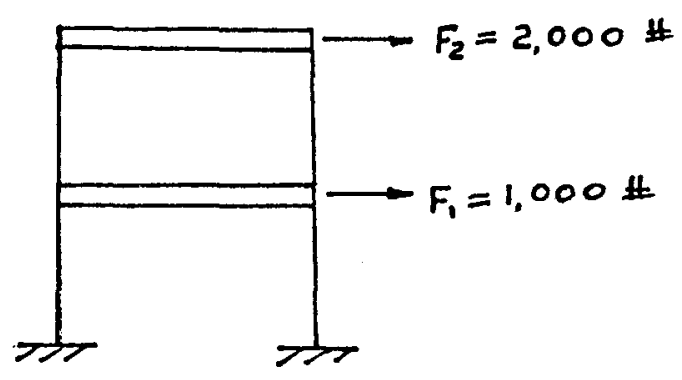

FIGURE 4 - Building Subjected to Constant Loading 
The values of natural frequencies, and the modes are known by solving the building as free vibration. This was shown in a numerical example in the preceding chapter. These values are:

$$
\begin{array}{lll}
\omega_{1}=178.5 \mathrm{rad} / \mathrm{sec} & \phi_{11}=0.9670 & \phi_{21}=-0.18 \\
\omega_{2}=56.02 \mathrm{rad} / \mathrm{sec} & \phi_{12}=0.2545 & \phi_{22}=0.6838
\end{array}
$$

To determine the appropriate functions $Z_{1}(t)$ and $Z_{2}(t)$, which will enable to uncouple equation (21), it is necessary to use equation (23), by substituting into (25) the numerical values found in the preceding chapter, gives

$$
\begin{gathered}
P_{1}-0.967(1000)+(-0.18)(2,000)=607 \\
P_{2}=0.254(1000)+(0.6838)(2,000)=1,621.6
\end{gathered}
$$

Performing the numerical substitution in equation (23) yields,

$$
\begin{gathered}
\ddot{z}_{1}+(178.5)^{2} z_{1}=607 \\
\ddot{z}_{2}+(56.02)^{2} z_{2}=1,621.6
\end{gathered}
$$

Since it was assumed that $F_{1}(t)$ and $F_{2}(t)$ are constant loading applied suddenly at time equal zero the solution of the above equations is given by

$$
\begin{aligned}
& z_{1}(t)=\frac{p_{1}}{\omega_{1}}\left(1-\cos \omega_{1} t\right)=\frac{607}{31,862.25}(1-\cos 178.5 t) \\
& z_{2}(t)=\frac{p_{2}}{\omega_{2}}\left(1-\cos \omega_{2} t\right)=\frac{1,621.6}{3,138.24}(1-\cos 56.02 t)
\end{aligned}
$$


and the maximum displacement by

$$
\begin{aligned}
& Z_{1 \max }=(2) \frac{P_{1}(t)}{\omega_{1}}=(2) \frac{607}{31,862.25}=0.038 \\
& Z_{2 \max }=(2) \frac{P_{2}(t)}{\omega_{2}}=(2) \frac{1,621.6}{3,138.24}=1.032
\end{aligned}
$$

A method which is widely accepted and which gives a good estimation of the maximum response from the spectrum values is the square root of the sum of the squares of the modal contributions. This calculation is given by

$$
\begin{aligned}
& x_{1 \text { max }}=\sqrt{\left(\phi_{11} Z_{1 \text { max }}\right)^{2}+\left(\phi_{12^{2} Z_{\text {max }}}\right)^{2}} \\
& x_{2 \text { max }}=\sqrt{\left(\phi_{12^{2} Z_{\text {max }}}\right)^{2}+\left(\phi_{22^{2} Z_{\text {max }}}\right)^{2}}
\end{aligned}
$$

which upon substitution gives,

$$
\begin{aligned}
& x_{1 \text { max }}=\sqrt{(0.9670 \times 0.038)^{2}+(0.2545 \times 1.032)^{2}}=0.2652 \\
& x_{2 \max }=\sqrt{(-0.180 \times 0.038)^{2}+(0.6838 \times 1.032)^{2}}=0.7057
\end{aligned}
$$

\section{Response of a Shear-Building to Ground Motion}

The response of a shear building to the base or foundation motion is conveniently obtained in terms of relative displacements with respect to the base motion.

For a two-story shear building shown in Figure. 5 a which has its mathematical model shown in Figure $5 \mathrm{~b}$, the equations of motion are obtained by applying Newton's second law to Figure $5 b$ as follows, 


\section{0}

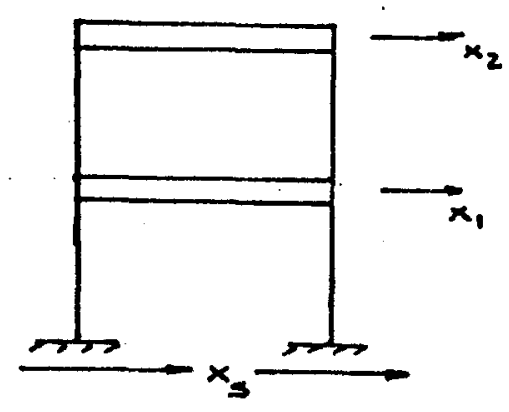

FIGURE 5(a) - Shear Building Subjected to Ground Motion

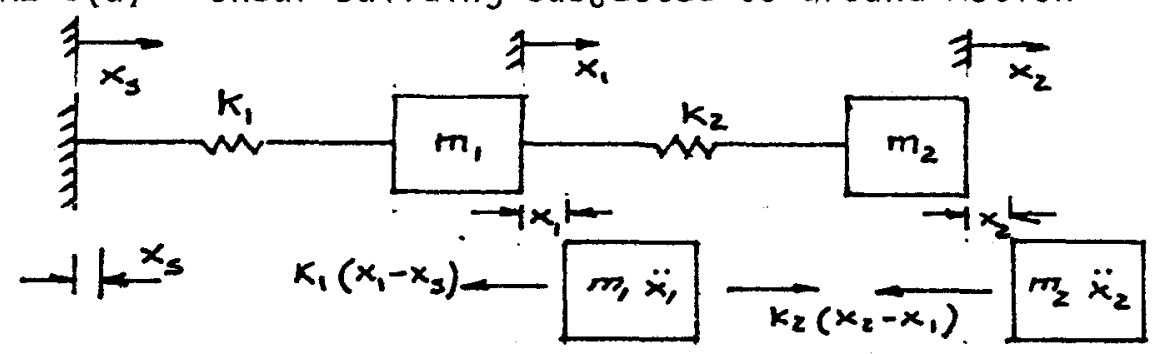

FIGURE 5(b) - Mathematical Model and its Free Body Diagram

$$
\begin{gathered}
m_{1} \ddot{x}_{1}+k_{1}\left(x_{1}-x_{5}\right)-k_{2}\left(x_{2}-x_{1}\right)=0 \\
m_{2} \ddot{x}_{2}+k_{2}\left(x_{2}-x_{1}\right)=0
\end{gathered}
$$

where $x_{S}=x_{S}(t)$ is the displacement imposed to the base of the structure. Expressing the displacements in terms of relative displacements,

$$
\begin{aligned}
& u_{1}=x_{1}-x_{s} \\
& u_{2}=x_{2}-x_{s}
\end{aligned}
$$

and derivading (28) twice with respect to time yields,

$$
\begin{aligned}
& \ddot{x}_{1}=\ddot{u}_{1}+\ddot{x}_{s} \\
& \ddot{x}_{2}=\ddot{u}_{2}+\ddot{x}_{5}
\end{aligned}
$$


By substituting (28) and (29) into (27) gives,

$$
\begin{gathered}
m_{1} \ddot{u}_{1}+\left(k_{1}+k_{2}\right) u_{1}-k_{2} u_{2}=-m_{1} \ddot{x}_{s} \\
m_{2} \ddot{u}_{2}-k_{2} u_{1}+k_{2} u_{2}=-m_{2} \ddot{x}_{s}
\end{gathered}
$$

For a base motion of shear building equations (29) may be written as,

$$
\begin{aligned}
& \ddot{z}_{1}+w_{1}^{2} z_{1}=\frac{-m_{1} a_{11}+m_{2} a_{21}}{m_{1} a_{11}^{2}+m_{2} a_{21}^{2}} \ddot{x}_{s}(t) \\
& \ddot{z}_{2}+w_{2}^{2} z_{2}=\frac{-m_{1} a_{12}+m_{2} a_{22}}{m_{1} a_{12}^{2}+m_{2} a_{22}^{2}} \ddot{x}_{s}(t)
\end{aligned}
$$

in a compact form gives,

$$
\begin{aligned}
& \ddot{z}_{1}+\omega_{1}^{2} z_{1}=\Gamma_{1} \ddot{x}_{s}(t) \\
& \ddot{z}_{2}+\omega_{2}^{2} z_{2}=\Gamma_{2} \ddot{x}_{s}(t)
\end{aligned}
$$

where $\Gamma_{1}$ and $\Gamma_{2}$ are called the participation factors which are represented by

$$
\Gamma_{1}=\frac{-m_{1} a_{11}+m_{2} a_{21}}{m_{1} a_{11}^{2}+m_{2} a_{21}^{2}} \text { and } r_{2}=\frac{-m_{1} a_{12}+m_{2} a_{22}}{m_{1} a_{12}^{2}+m_{2} a_{22}^{2}}
$$

The relation between the modal displacement $z_{1}, z_{2}$ and the relative displacement $u_{1}, u_{2}$ is given in equation (20) as

$$
\begin{aligned}
& u_{1}=a_{11} z_{1}+a_{12} z_{2} \\
& u_{2}=a_{21} z_{1}+a_{22} z_{2}
\end{aligned}
$$


The change of variable to make the second member of equation (32) equal $x_{s}(t)$, take the form of

$$
\begin{array}{ll}
z_{1}=r_{1} & g_{1} \\
z_{2}=r_{2} & g_{2}
\end{array}
$$

substituting (35) into (32) gives

$$
\begin{aligned}
& \ddot{g}_{1}+\omega_{1}^{2} g_{1}=\ddot{x}_{s}(t) \\
& \ddot{g}_{2}+w_{2}^{2} g_{2}=\ddot{x}_{s}(t)
\end{aligned}
$$

Finally, solving for $g_{1}(t)$ and $g_{2}(t)$ the uncoupled equation (36) and substituting this solution into (34) and (35) gives

$$
\begin{aligned}
& u_{1}(t)=\Gamma_{1} a_{11} g_{1}(t)+\Gamma_{2} a_{12} g_{2}(t) \\
& u_{2}(t)=\Gamma_{1} a_{21} g_{1}(t)+\Gamma_{2} a_{22} g_{2}(t)
\end{aligned}
$$

Whenever the maximum modal response $g_{1 \max }$ and $g_{2 \max }$ are obtained from spectral charts, the maximum values of $u_{1 \max }$ and $u_{2 \max }$ can be obtained by using (26) in the following form:

$$
\begin{aligned}
& u_{1 \text { max }}=\sqrt{\left(\Gamma_{1} a_{11^{g}}{ }_{1 \text { max }}\right)^{2}+\left(\Gamma_{2} a_{21} g_{2 \max }\right)^{2}} \\
& u_{2 \max }=\sqrt{\left(\Gamma_{1}{ }_{12^{g}}{ }_{1 \text { max }}\right)^{2}+\left(\Gamma_{2}{ }_{22} g_{2 \max }\right)^{2}}
\end{aligned}
$$

\section{Subroutine Modal}

This modal is utilized to obtain the response of multiple degree of freedom system by using the superposition methoc. The theory and the 
manipulation was shown throughout this chapter. The symbols for this subroutine are shown below.

\begin{tabular}{|c|c|c|}
\hline Variables & Symbols in Thes is & Description \\
\hline ND & $\mathrm{N}$ & Number of degrees of freedom \\
\hline GR & $\mathrm{g}$ & $\begin{array}{l}\text { Excitation index: For support excita- } \\
\text { tion, g-acceleration of gravity. For } \\
\text { forced excitation, } g=0 \text {. }\end{array}$ \\
\hline $\operatorname{EIGEN}(\mathrm{I})$ & $\omega_{i}^{2}$ & $\begin{array}{l}\text { Square of natural frequencies (eigen- } \\
\text { values) }\end{array}$ \\
\hline$X(I, J)$ & $|\Phi|$ & Modal matrix (eigen-vectors) \\
\hline DT & & Time step of integration \\
\hline TMAX & & Maximum time of integration \\
\hline$N Q(L)$ & & $\begin{array}{l}\text { Number of points defining the excita- } \\
\text { tion at coordinate } L\end{array}$ \\
\hline$M(I, J)$ & & Mass matrix \\
\hline$T(I)$ & $t_{i}$ & Time at point $i$ \\
\hline$P(I)$ & $P\left(t_{i}\right)$ & Force or acceleration at time $t_{i}$ \\
\hline $\mathrm{XIS}(\mathrm{I})$ & $\xi_{i}$ & Damping ratios \\
\hline
\end{tabular}

The input data are subjected to the following formats.

\begin{tabular}{ll}
\hline Format & \multicolumn{1}{c}{ Variables } \\
\hline$(I 10, F 10.0)$ & $N D, G R$ \\
$(8 F 10.4)$ & $M(I, J)$ (read by rows) \\
$(8 F 10.4)$ & $E I G E N(I),(I=1, N D)$ \\
$(8 F 10.4)$ & $X(I, J)$ (read by rows) \\
$(2 F 10.4,1215)$ & DT, TMAX, NQ(L) (L=1...NG), where NG=ND when forces \\
& are at coordinates or NG=I when acceleration is at \\
support & t(I), P(I) (I=1,NQ(L)) (one card per forcing func- \\
$(8 F 10.2)$ & tion) \\
$(8 F 10.3)$ & 2SI $(I),(I=1, N D)$ \\
\hline
\end{tabular}




\section{DAMPED MOTION OF SHEAR BUILDING}

In the previous chapter the analysis of a shear building was based upon undamped system of motion; the techniques to determine the response of the shear building were discussed, giving special emphasis on the tranformation from coupled systems to uncoupled systems, by means of a transformation of coordinates which incorporate the property known as orthogonality of the modal shapes.

In the consideration of damping forces in the dynamic analysis of shear building presented in this chapter, the system of equations of motion became more complicated, not only because the system will contain one more forcing factor, but the procedure to uncouple the system will also become difficult. One way to avoid this difficulty is by introducing some restrictions or conditions on the functional expression for the coefficients of damping.

For practical purposes, damping is neglected for the calculation of natural frequencies and modal shapes of the system. Consequently for the solution of the Eigenvalue problem the system is reduced to an undamped and free vibration system.

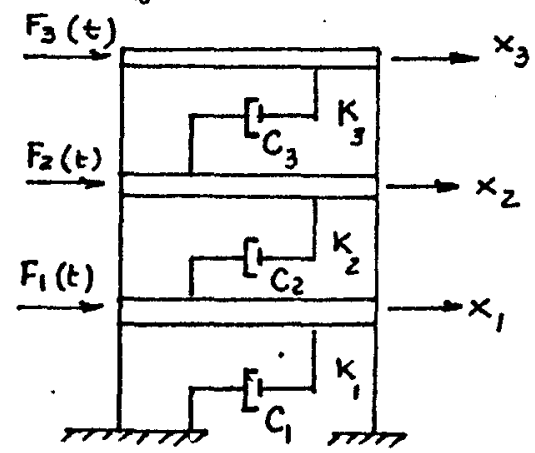

FIGURE 6(a) - Shear Building Subjected to Damped Motion 


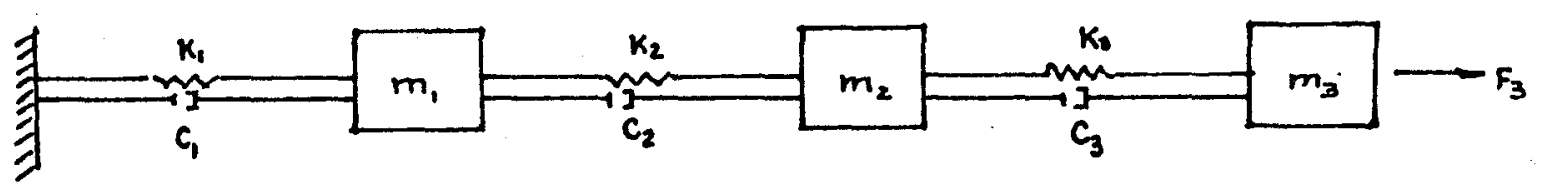

FIGURE 6(b) - Mathematical Model of Shear Building

\section{A. Equation of Motion for Damped System}

For a viscously damped three-story shear building shown in Figure $6(a)$ the equation of motion can be obtained by applying Newton's second law to the free body diagram of the mathematical model shown in Figure $6(\mathrm{~b})$; these equations are,

$$
\begin{gathered}
m_{1} x_{1}+c_{1} \dot{x}_{1}+k_{1} x_{1}-c_{2}\left(\dot{x}_{2}-\dot{x}_{1}\right)-k_{2}\left(x_{2}-x_{1}\right)=F_{1}(t) \\
m_{2} \ddot{x}_{2}+c_{2}\left(\dot{x}_{2}-\dot{x}_{1}\right)+k_{2}\left(x_{2}-x_{1}\right)-c_{3}\left(\dot{x}_{3}-\dot{x}_{2}\right)-k_{3}\left(x_{3}-x_{2}\right)=F_{2}(t) \\
m_{3} \ddot{x}_{3}+c_{3}\left(\dot{x}_{3}-\dot{x}_{2}\right)+k_{3}\left(x_{3}-x_{2}\right)=F_{3}(t)
\end{gathered}
$$

in matrix form

$$
[M]\{\ddot{x}\}+[c]\{x\}+[K]\{x\}=\{F(t)\}
$$

where the only new factor introduced is the damping matrix [c] which is given by 


$$
[c]=\left[\begin{array}{ccc}
c_{1}+c_{2} & -c_{2} & 0 \\
-c_{2} & c_{2}+c_{3} & -c_{3} \\
0 & -c_{3} & c_{3}
\end{array}\right]
$$

Since, equation (40) is obviously a coupled system of equations, then it is convenient to uncouple by introducing the following transformation of coordinates:

$$
\{x\}=[\Phi]\{Z\}
$$

where $[\Phi]$ is the modal matrix obtained by solving the system as undamped free vibration, substituting (41) into (40) gives,

$$
[n][\Phi]\{\ddot{Z}\} \quad[C][\Phi]\{Z\} \quad[K][\Phi]\{Z\} \quad\{F(t)\}
$$

Premultiplying (42) by the transpose of the nth modal vector $\{\Phi\}_{n}^{\top}$ yields

$$
\{\Phi\}_{n}^{\top}[M][\Phi]\{\ddot{Z}\}+\{\Phi\}_{n}^{\top}[C][\Phi]\{\dot{Z}\}+\{\Phi\}_{n}^{\top}[K][\Phi]\{Z\}=\{\Phi\}_{n}^{\top}\{F(t)\}
$$

.It is noticed that the orthogonality property of the modal shapes, is given by

$$
\begin{gathered}
\{\Phi\}_{n}^{\top}[M]\{\Phi\}_{m}=0 \\
\{\Phi\}_{n}^{\top}[K]\{\Phi\}_{m}=0, m \neq n
\end{gathered}
$$

Causing all components except the nth mode in the first two terms of (43) to vanish. A similar reduction is assumed to apply to the damping 
term in (43) that is

$$
\{\Phi\}_{n}^{T}[C]\{\Phi\}_{m}=0 \quad n \neq m
$$

then the coefficient of the damping term in (43) will reduce to $\{\Phi\}_{n}^{\top}[C]\{\Phi\}_{n}$; therefore (43) gives

$$
M_{n} \ddot{z}_{n}+c_{n} \dot{z}_{n}+K_{n} z_{n}=F_{n}(t)
$$

or

$$
\ddot{z}_{n}+z_{n} \omega_{n} \dot{z}_{n}+\omega_{n}^{2} z_{n}=\frac{F_{n}(t)}{M_{n}}
$$

in which

$$
\begin{gathered}
M_{n}=\{\Phi\}_{n}^{\top}[M]\{\Phi\}_{n} \\
K_{n}=\{\Phi\}_{n}^{\top}[K]\{\Phi\}_{n}=\omega_{n}^{2} M_{n} \\
C_{n}=\{\Phi\}_{n}^{\top}[C]\{\Phi\}_{n}=2 \xi \omega_{n} M_{n} \\
F_{n}(t)=\{\Phi\}_{n}^{T}\{F(t)\}
\end{gathered}
$$

The normalization that was presented previously

$$
\{\Phi\}_{n}^{\top}[M]\{\Phi\}_{n}=1
$$

will give $M_{n}=1$, so that (46) will reduce to

$$
\ddot{z}_{n}+2 \xi \omega_{n} \dot{z}+\omega_{n}^{2} z_{n}=F_{n}(t)
$$

which is a set of uncoupled differential equations. 
B. Conditions to Uncoupled Equations in Damped Systems

The derivation of equation (49) was based upon the assumption that damping can also be uncoupled by using the normal coordinate transformation utilized to uncouple the inertial and elastic forces.

It is crucial, at this point to explain the condition under which this uncoupling will occur, that is, the form of the damping matrix [C] to which (45) applies.

Rayleigh showed that in damping matrix of the form

$$
[C]=a_{0}[M]+a_{1}[K]
$$

in which $a_{0}$ and $a_{1}$ are proportionality factors, the orthogonality condition will be satisfied, that is, premultiplying both sides of (50) by the transpose of nth mode $\{\Phi\}_{n}^{\top}$ and postmultiplying by the modal matrix [థ] gives equation (51) as follows:

$$
\{\Phi\}_{n}^{T}[C][\Phi]=a_{0}\{\Phi\}_{n}^{\top}[M][\Phi]+a_{1}\{\Phi\}_{n}^{T}[K][\Phi]
$$

with the orthogonality condition (44) equation (51) reduces to

$$
\{\Phi\}_{n}^{T}[C][\Phi]=a_{0}\{\Phi\}_{n}^{\top}[M][\Phi]+a_{1}\{\Phi\}_{n}^{T}[K][\Phi]
$$

or by (47) equation (51) takes the following form

$$
\begin{aligned}
& \{\Phi\}_{n}^{T}[C][\Phi]=a_{0} M_{n}+a_{1} M_{n} \omega_{n}^{2} \\
& \{\Phi]_{n}^{\top}[C][\Phi]=\left(a_{0}+a_{1} \omega_{n}^{2}\right) M_{n}
\end{aligned}
$$


which shows that, when the damping matrix [C] is of the form (50), the damping is coupled with equation (41). It can also be shown that [M] and $[K]$ satisfy the orthogonality condition. In general, it takes the form

$$
[C]=[M] \sum_{i} \text { ai }\left([M]^{-1}[K]\right)^{i}
$$

in which as many terms may be included as desired.

Rayleigh damping equation (50) obviously is contained in equation (53); however, by including additional terms in this equation it is possible to obtain a greater degree of control over the modal damping ratios resulting from damping matrix. With this type of damping matrix it is possible to compute the damping influence coefficients necessary to provide a decouple system having any desired damping ratios in any specified number of modes. For each mode $n$, the generalized damping is given by equation (54) of the following form

$$
C_{n}=\{\Phi\}_{n}^{T}[C]\{\Phi\}_{n}=2 \Sigma_{n} \omega_{n} M_{n}
$$

But if $[\mathrm{C}]$ as given by equation (53) is substituted in the expression for $C_{n}$, the series of generalized damping is

$$
c_{n}=\{\Phi\}_{n}^{T}[M]_{i} \Sigma a_{i}\left([M]^{-1}[K]^{i}\{\Phi\}_{n}\right)
$$

Now, by using the equation of motion as free vibration $[K]\{a\}=\omega^{2}[M]\{a\}$ after normalized $K\{\Phi\}_{n}=\omega^{2} M\{\Phi\}_{n}$ and performing the necessary algebra it 
is possible to show that the damping coefficient associated with any mode $n$ may be written as

$$
c_{n}=\sum_{i} a_{i} \omega_{n}^{2 i} M_{n}=2 \xi_{n} \omega_{n} M_{n}
$$

from which the damping ratio can be given as

$$
\xi_{n}=\frac{1}{2 \omega_{n}} \sum a_{j} \omega_{n}^{2 i}
$$

Equation (57) may be used to determine the constants $a_{i}$ for any desired values of modal damping ratios corresponding to any specified numbers of modes. For instance, to evaluate the first four damping ratios $\xi_{1}, \xi_{2}$, $\xi_{3}$, and $\xi_{4}$ in this case (57) gives the following equation

$$
\left[\begin{array}{l}
\xi_{1} \\
\xi_{2} \\
\xi_{3} \\
\xi_{4}
\end{array}\right]=1 / 2\left[\begin{array}{llll}
\omega_{1} & \omega_{1}^{3} & \omega_{1}^{5} & \omega_{1}^{7} \\
\omega_{2} & \omega_{2}^{3} & \omega_{2}^{5} & \omega_{2}^{7} \\
\omega_{3} & \omega_{3}^{3} & \omega_{3}^{5} & \omega_{3}^{7} \\
\omega_{4} & \omega_{4}^{3} & \omega_{4}^{5} & \omega_{4}^{7}
\end{array}\right]\left[\begin{array}{l}
a_{1} \\
a_{2} \\
a_{3} \\
a_{4}
\end{array}\right]
$$

In general (58) may be expressed symbolically and in condensed form as follows

$$
\{\xi\}=1 / 2[Q]^{-1}\{a\}
$$

from which it is possible to get the constant $\{a\}$ as

$$
\{a\}=2[Q]^{-1}\{\xi\}
$$


Finally, the damping matrix is obtained after the substitution of equation (60) into (53).

It is interesting to observe from equation (57) that in the special case when the damping matrix is proportional to the mass $\{C\}=a_{0}[M]$ when $i=0$, the damping ratios are inversely proportional to the natural frequencies; thus the higher modes of the structure will be given very little damping.

There is yet a second method for evaluating the damping matrix corresponding to any set of specified modal damping ratio. This method is presented starting with the following relationship

$$
[A]=[\Phi]^{T}[C][\Phi]=\left[\begin{array}{ccc}
2 \xi_{1} \omega_{1} M_{1} & 0 & 0 \\
0 & 2 \xi_{2}{ }^{\omega_{2} M_{2}} & 0 \\
0 & 0 & 2 \xi_{3}{ }^{\omega_{3} M_{3}} \\
\ldots \ldots \ldots \ldots \ldots \ldots \ldots \ldots
\end{array}\right]
$$

It is evident that the damping matrix [C] may be evaluated by pre-and post-multiplying (61) by the inverse of the modal matrix and its inverse transpose, such that

$$
[C]=[\Phi]^{-T}[A][\Phi]^{-1}
$$

Therefore, for any specified set of modal damping ratios $\{\xi\}$, matrix $[A]$ can be evaluated from (61) and damping matrix [C] from (62). However, in practice, the inversion of modal matrix is a tedious task. But taking advantage of orthogonality properties of the mode shapes, the following expression can be deduced. 


$$
[C]=[M]\left(\sum_{n=1}^{N} \frac{2 \xi_{n} \omega_{n}}{M_{n}}\{\Phi\}_{n}\{\Phi\}_{n}^{\top}\right)[M]
$$

The damping matrix [C] obtained from (63) will satisfy the property of orthogonality and therefore, the damping term in equation (40) will be uncoupled with the same transformation (41) which serves to uncouple the inertial and elastic forces.

\section{Subroutine Damp}

This subroutine developed by Professor Paz calculates the system damping [C] using (63) from specified modal damping ratios. The main program gives the values of $[\Phi]$ and $[M]$ to the subroutine, but, the damping ratio should be given, with the following input format.

\begin{tabular}{lcccc}
\hline Variable & Symbol in Text & Format & Description \\
\hline$x(I)$ & $\xi$ & $8 F 10.2$ & $\begin{array}{c}\text { Damping ratio for } \\
\text { modes } 1 \text { to } \mathrm{NL}\end{array}$ \\
\hline
\end{tabular}

The past experience indicates that values for the modal damping ratios in structures are generally in the range of $2 \%$ to $10 \%$, probably no more than $20 \%$. Therefore for a 11 practical purposes in a design of a dynamic structure the engineer takes $10 \%$ as a typical figure.

D. Seismic Response of an Elastic Shear Building

The computer program that is presented in this section, calculates the dynamic response of a shear building, within the linearelastic range and subjected to excitation at its foundation. The modal superposition method of analysis is utilized to uncouple the system of differential equations. Subroutine Jacobi, developed by Professor Wilson, 
is called to solve the eigenproblem resulting in eigenvalues $\left(\omega_{i}^{2}\right)$ and the eigenvectors which form the modal matrix $[\Phi]$. Subroutine Modal, which is called next, solves the resulting modal equations using Duhamel's integral described by Professor Paz in Chapter 4 of Structural Dynamics. Finally at each step, the solution of the modal equations are combined in equation (41) to obtain the response in terms of the original coordinates of the shear building.

The variables and input formats used in this program are shown in tabular form below.

\begin{tabular}{lll}
\hline Variable & Symbol in Thesis & \multicolumn{1}{c}{ Description } \\
DT & $\Delta t$ & Time increment \\
$E$ & $E$ & Modules of elasticity \\
GR & $g$ & Acceleration of gravity \\
TMAX & & Maximum time response \\
NEQ & & $\begin{array}{l}\text { Number of points of the excitation } \\
\text { function }\end{array}$ \\
ND & & Number of degrees of freedom \\
IFPR & & Index for intermediate printing in \\
Jacobi; $1=$ Print, $0=$ do not print
\end{tabular}

These variables are subjected to the following input formats. 
Formats

Variables

$(4 F 10.2,255) \quad$ DT, E, GR, TMAX, NEQ, ND

(3F10.2)

$S I, S L, S M(I, I)$ (one card for each story)

$(8 \mathrm{~F} 10.2)$

TC(1), $P(1), T C(2), P(2) \cdots T C(N E Q), P(N E Q)$ 
E. Computer Program \#1

SUCP $\quad$ DAGES $=5, T T M E=5, L ! N E S=400$

C

c

c

STISHER RESFCMSE ELASTIC SHEAR AUILOING

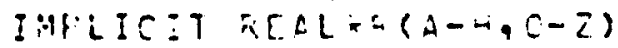

DIMENS:CN: SK(30,3J), EM (30, 30$), S C(30,30), F(30), \times(30,20)$,

C 1 JUA $(30), 1 ! n(30), U V(20), 114(30), T C(30), F(30), \leq(30), E: C E:(30)$

C REAO IYFUT OLTA AME IYITIALIZE

C

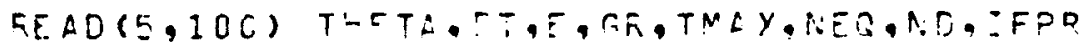

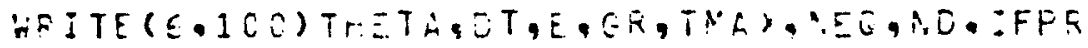

100 FORVAT $(?=10.2 \cdot 2=10 \cdot 0,=10.2,3 \mathrm{IE})$

$\therefore X=T \vee a ; 10 T+2$

$001 \quad I=1, \therefore x$

$1 F(!)=0 \cdot 0$

OC $2 \quad I=1, \cdots C$

DO $2 \quad J=1,00$

$\operatorname{Sin}(I, J)=0.0$

$S C(I, J)=0.0$

$x(z, 7)=0.0$

$2 \operatorname{SK}(I \cdot J)=0.0$

ND1 $=80+1$

$T U=T H E T A+E T$

$\Delta I=3.1 T U$

$A 2=5 \cdot 1 \mathrm{TU}$

$\Delta 3=T U / 2$.

$A 4=A 2 / T U$

$007 \quad I=1 \cdot \therefore$

REAS(5,110) SE,SL,SM(Z,I)

ULITE(E, 110$) \leq E, S 1, S M(:, T)$

110 FSFNAT(ZF10.2,F 10.0$)$

$S(I)=12 \cdot 0 \cdot 5 \div S I / S L \div+3$

$S C(I, j)=s: \because(I, Z)$

$U D(I)=c .0$

7 UV $(I)=0,0$

c

$c$

C

DSSEMBLE STIFFNESS MATRIX

$S(V D+1)=0.0$

c) $15:=1 \cdot 0$

IF $(1.50 .1)$ GO TO IS

$S K(i, j-1)=-S(?)$

$S K(I-1, i)=-S(:)$

$19 \operatorname{SK}(i, i)=S(:)+5(I+1)$

C

c.

DETERVINE YATUGAL FOEQUEVIEIES DVO MEDE SHAFES

CALL JACOEZ(SK, SC,X,EIGEM,TC, NO, IFPE)

c

c

C

DETERMINE GANPT:UG NATR:X

CALL DAYP(NE, X,SM.SE.EIGSA)

$c$

c

INTERPRLATTRA EFTLER. OATA OJINTS

REAO $(S, 12 C) \quad(T C(L), F(L), L=1, \therefore T O)$

WRITE(S, $12 C)(T C(L), F(L) \cdot L=1, N(E)$

100 FERMLT(4FI).?

DO $4:-1 \times 10$

$4 P(I)=f(I) \cdot(, F$ 
c

c.

$\because A \because U=A Y Q T+D T$

$F(I)=P(I I)+(P(T I+1)-D(I I)) * A N M /(T C(I I+1)-T C(I I))$

10 CONTIUIS

16 CONTINE

c

CALCULATE INITIAL ACCELERATIOA

$N T=T N A \times 10 T$

Co $22 \quad y=1$. ive

$X(1, \log 1)=-F(1)+\operatorname{SN}(I, T)$

C) $22 \quad j=1.00$

$22 \times(i, J)=\{\because(\Sigma, j)$

C $\quad$ OC $301 \mathrm{~L}:=1, \mathrm{CO}$

C 301 V!RETE $(E, 2 I C)$ (X(LI,LJ),LJ=1,N:II)

CALL SELVE $(S E, x)$

c

HRITE(S,21?) (X(LI, NCI) -LI=1,ND)

DO $23 \quad i=1,90$

$23 U A(i)=x(:, 101)$

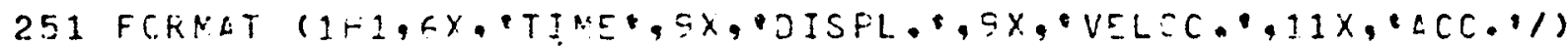
HRITE $(6,251)$

$c$

c

STEP EY STEP LOCP TO CFLCULATE RESFENSE

$0 \cap \geqslant 0 \quad L=1, P T$

$A L=L$

$T=E T * 4 !$

$D=20:=1, \triangle 0$

IF $(i .50 .1)$ ot TC 20

SK $(T, i-1)=-S(\Sigma)$

$S K((I-1), i)=-S(I)$

$20 S K(I, I)=S(I)+S(I+1)$

DO $65 \quad 1=1, \therefore 0$

C2 $25 \quad J=1,0$

$25 \times(I, U)=S K(I, J)+A 4+3 \times(i, J)+A 1+s C(i, J)$

$0235:=1,90$

$X(I, \cap O Z)=(F(L+1)+C F(L+2)-F(L+1)) *(T H E T A-1 \cdot O)-F(L))+(-S M(I, I))$ $0.030 \quad 3=1, \because 4$

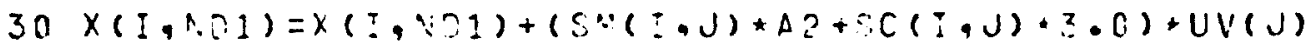

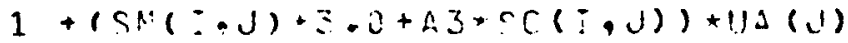

JE CONTIUUS

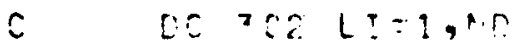

C 302 WR!TE(6, 2IE) (X(LT,LU),LJ=1, NE1)

CALL SCLVE $(\because 0, x)$

C HRITE(S,EIC: $(\times(L I, D D 1), L I=1, M)$

DC $3 \dot{E} \quad !=1, \quad \mathrm{~N}$.

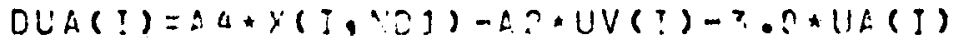

DUA (I) $=$ OULC(I)/THET: 


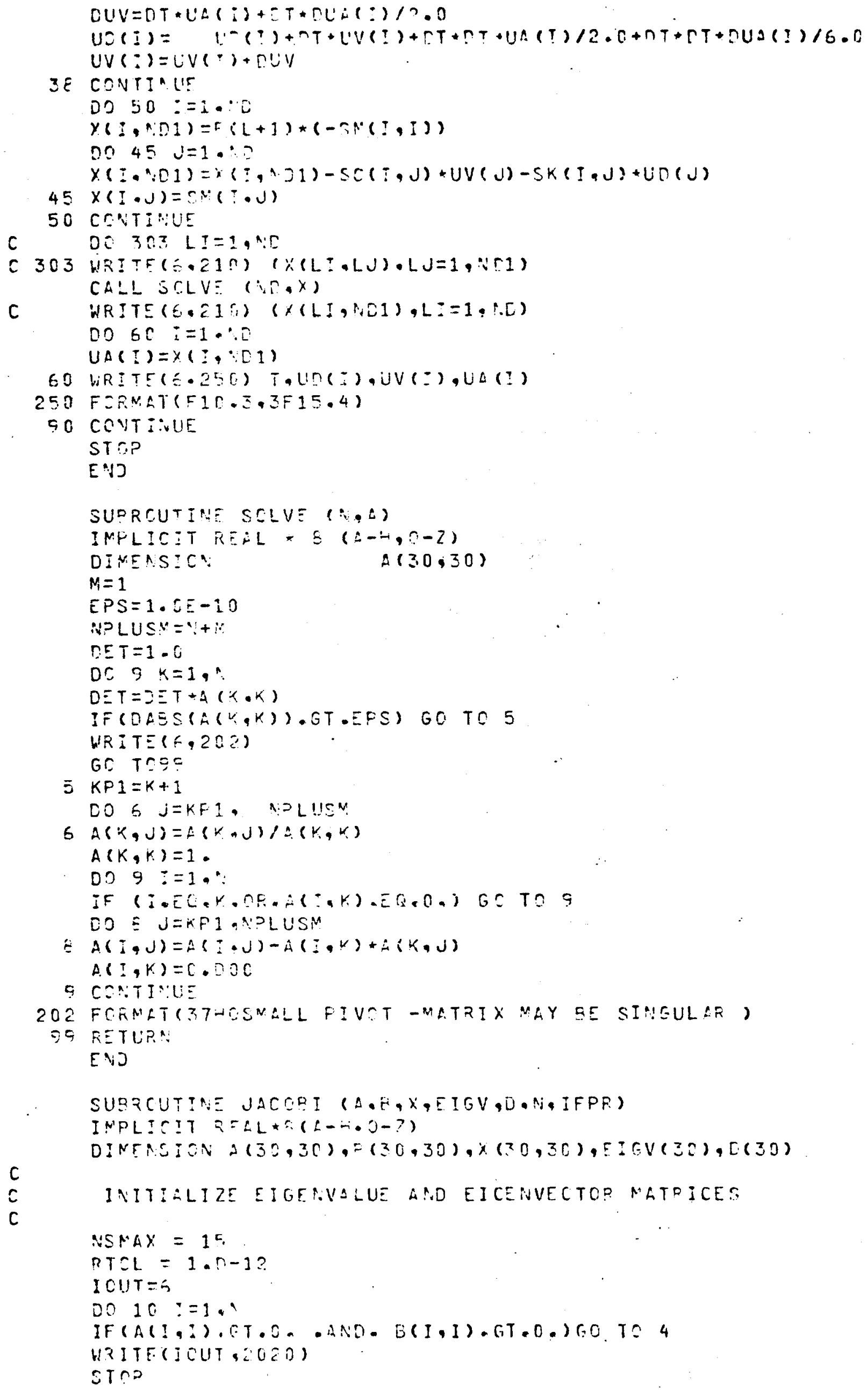


$4 D(I)=L(i, Z) / C(i, I)$

$10 \quad 5 \operatorname{IgV}(:)=0(:)$

$00301=1, "$

D. $20 \quad J=1 . n^{\circ}$

$20 \times(I, J)=0$.

$30 \times(I, I)=$.

IF $\left(N_{i} \cdot E-C \cdot 1\right)$ RETUR:!

C

C

C

C

C

$\mathrm{C}$

c

IVITIALIZS SHEEF CEURTEP AND EEGEN ITE:ATICA

¿SW $S E \Omega=0$

$N R=N-1$

40 ASWEEP $=N S W F E F+1$

IF (IFPF E -1) UPETE(ICUT, 2000$)$ ISWEEF

CHECK IF PRESEMT OFF-DEAGONAL ELENEVT IS LARGE

$E P S=(+01 * \because E U E F F)=2$

DO $210 \quad J=3,1: R$

$J J=J+1$

CO $210 k=J U, k$

EPT JLA $=(A(U, K) * A(J, K))((A, J, J)+A(K, K))$

EPTOL $\Xi=(O(J, K)+F(J, K)) /(P(J, J) \star E(K, K))$

IF( (EPTOLA.LT.EOS). AHE. (EPTOLE.LT.EPS)) GC TO21C

IF ZEROINE IS REQUTFED,CALCULATE THE ROTATICA MATRIX ELEMEMT CA.CE

$A K K=A(x, K)=E(J, K)-E(K, K)+\Delta(J, K)$

$A J J=A(J, J) \cdot S(J \cdot K)-E(J, J)=A(J, K)$

$A B=A(J, J) * E(K, K)-L(K, K) * E(J, J)$

$C H E C K=(\triangle P+2 B+4 .-4 K K+4 J U) / 4$.

IF $(C H E C K) \equiv 0,60,60$

50 WRITE (IOUT.2.020)

STR?

60 SQCHI=CSORT $($ CHECK)

$D 1=\triangle E / \because=+S C C H$

$02=A 8 / 2 \cdot-S D C H$

DE $Y=01$

IF $(D A 3 S(D \Omega), G T \cdot C A=S(D 1)) D E N=) 2$

$70 C A=0$.

IF $(D E S)=0 \cdot 7 C, \therefore 0$

$C G=-A(J, K) / A(K, K)$

$C E=-\dot{H}(u, k) / \dot{\mu}(k, k)$

GO TO $=0$

SO CA $=A K K / O E$.

$C G=-A J \cup / C=:$

c

c

C

50 IF $(:-2) 100,150,100$

100 JF $1=J+1$

$J M 1=J-1$

$K ? 1=K+1$

$K M 1=K-1$

I $F\left(J v_{1}-1\right), 1 ? 0,110,110$

110 OO $120 \quad:=1, v^{2}$

$A J=2(i, a)$

$B J=B(I, J)$

$A K=A(:, k)$

$B K=E(I, K)$

$A(I, J)=L J+C: A K$ 
$E(T, 7)=c 7+-r^{\circ}+E_{k}$

$A(i, k)=A K+C A * A J$

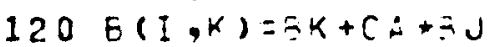

130 If $(K: 1-4) 140,140,15 C$

140 C2 $15.0 \quad I=K P 1, A$

$A J=\Delta(J \cdot I)$

$E J=5(J \cdot i)$

$A K=A(K, !)$

$B K=\bar{\partial}(K, T)$

$A(J, j)=2 u+C G \star 2 K$

$Q(J, \dot{B})=E J+C E+F K$

$A(K, I)=2 K+C A+2 J$

$150 \quad B(K, I)=B K+C \dot{\mu}+E_{j}$

IEC $I=(J>1-K M 1) 170.170,1 \subseteq 0$

170 DO $1 \div 0 \quad I=J=1 \cdot K Y_{1} 1$

$\dot{A} U=L\left(J_{*} ;\right)$

$B J=Z(J, I)$

$A K=A(I, K)$

$S K=E(E, K)$

$A(J, I)=A J+C G \cdot A K$

$B(J, I)=E J+C G \star E X$

$A(I, K)=E K+C A+A J$.

$1 \varepsilon 0 \quad E(I, K)=2 K+C a * E J$

$1 ; 0 \quad A K=A(K \cdot x)$

$B K=E(K, K)$

$A(K, K)=L K+2 . \star C * * L(J, K)+C A \star C A \star \Delta(J, J)$

$B(K, K)=P K+2 *(C E \equiv(J, K)+C A+C A * E(J, J)$

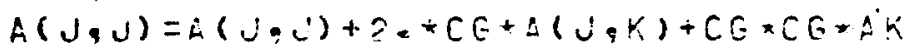

$B(u, u)=F(u, u)+2 .+C G+E(u, K)+C E+C G+E *$

$A(J, k)=0$.

$B\left(J, R_{i}\right)=0$.

C

C

C

UPDATE THE EIGE:UECTCI MATRIX AFTER ELCH POTATIOU:

0. $200 \quad:=1,: i$

$x J=x(! \cdot u)$

$X K=X(I, K)$

$x(I, J)=x J+C G+x k$

$200 \times(I, Y)=X K+C i * X, J$

c

210 CONTINUE

C

UPJATE THE EIGENVLLUES AFTER EACH SHEEF

C

DO $220 \quad I=1 .:$

IF (AS:IS.GT.O. . AND. P(I,I).GT.C.) GC TO 220

WPITEOI:UT. 20?3:

ST SP

220 EIGV(I)=4(I,I)/F(I,I)

IF(IFDG.EO. C)G? TS 230

URITE(:CUT, 20?0)

WRITE(:TUT, 2O1C) (ETGV(I), I I I,N)

C

C CHECK EEP COAVEDGENCE

$\mathrm{C}$

236 CO $24 n \quad I=1, A$

$T C L=R T C L+C(I)$

DTF =DAMS(F.GV(:)-T(I))

IF IDIF.GT A TCLSBC TC $2=0$ 
C

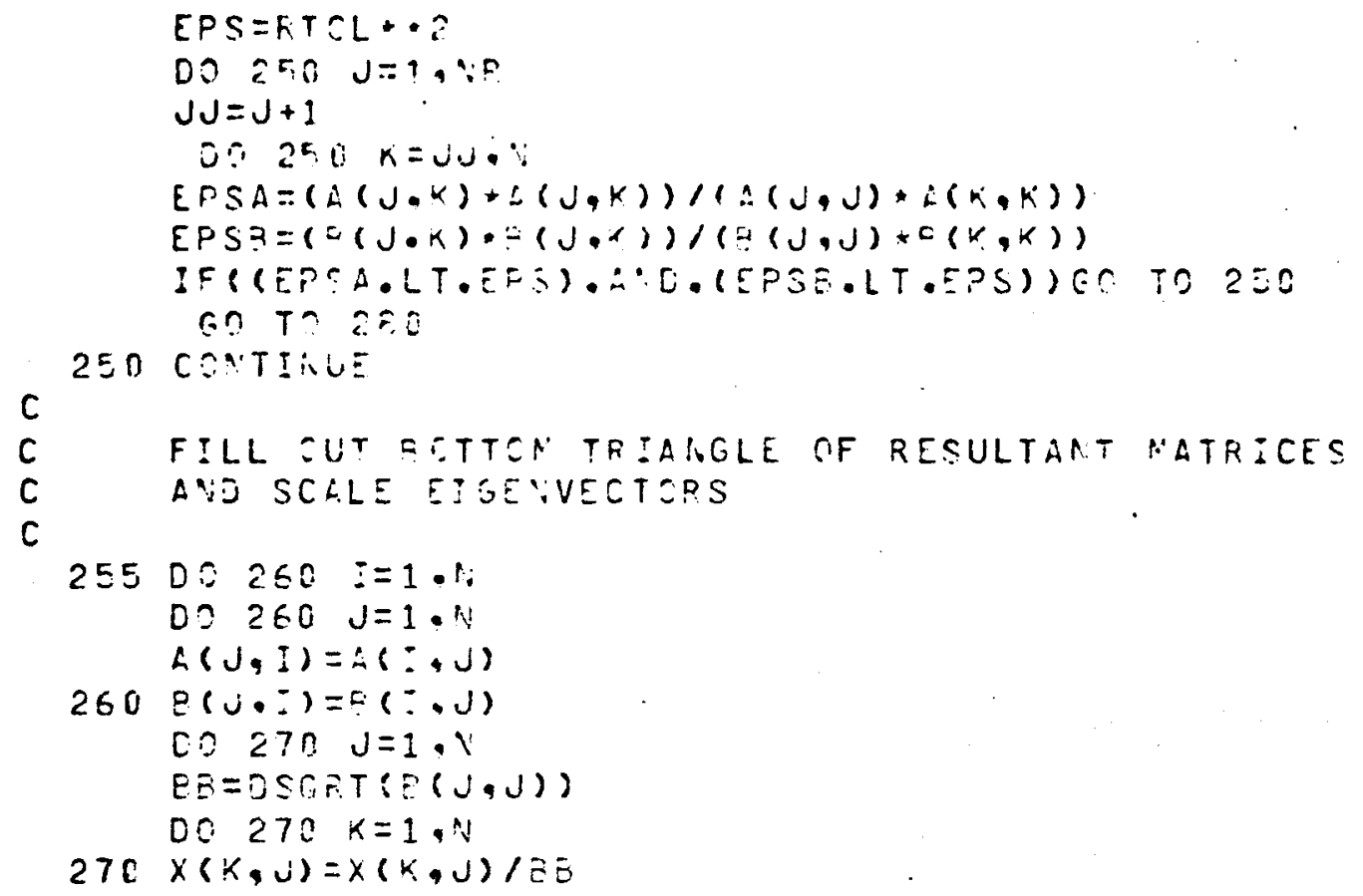




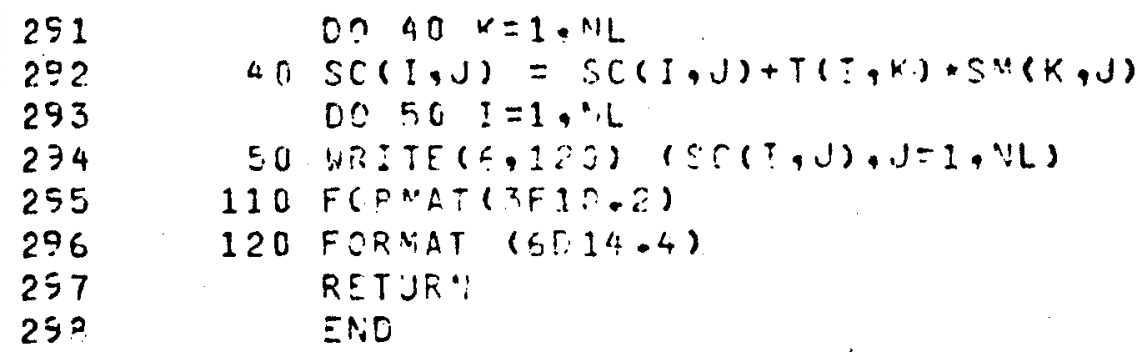

250

SENTRY.

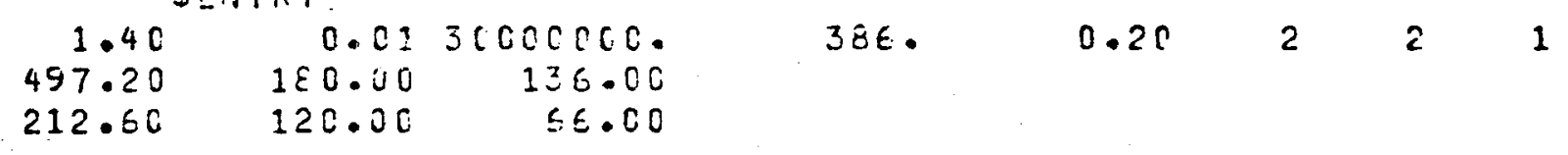

HEEP NUMEER IN +JACCE: + = 1

FUREATT EIEER.VALUES IN +JACEBI*ARE,

$60.139533 \equiv 512350 \quad 03 \quad 0.1552532747140 \quad 04$

MEEP NUMBER IN *UACOE:* $=2$

KURRENT E:CENVALUES IM *UACCEZ* ARE,

$0.1355558012350 \quad 03 \quad 0.1052532747140 \quad 04$

$0.643655 E 543450-01-0.5655205756620-01 \quad 0.8132300240065-01 \quad 0.9240175556810-0:$

0.00

C.0. 0

0.0000000

0.0000000

0.00
3.0000000

6. 00000 es

$0.26 \quad 1.00$
0.25 
TINE

\{c.010

0.010

0.020

0.620

6.030

0.050

to. 040

0.040

0.050

캐. 0.050

10.068

0.060

$\because 0.070$

0.070

0.000

0.030

$0.0=0$

$0.0 \equiv 0$

0.100

0.100

0.110

0.110

$0.12 \hat{c}$

0.120

0.130

.0 .130

0.140

0.140

0.150

0.152

10.165

$0.1 \leqslant c$

$0.17 \mathrm{C}$

0.170

$0.1 \div 0$

$0.1 \div 0$

$0.19 \hat{3}$

0.190

10.205

0.200
DISPL.

$-0.0054$

$-6.0054$

$-0.0215$

$-6.0217$

$-0.0478$

$-0.04 \div 5$

$-0.0 \div 3=$

$-0.0=66$

$-0.12 \% 1$

$-0.1351$

$-0.1 \div 23$

$-0.1940$

$-0.2426$

$-0.2 \leq 2 \equiv$

$-0.35 .3$

$-0.3412$

$-0.3=02$

$-0.4281$

$-0.4553$

$-6.5226$

$-0.5332$

$-0.6234$

$-0.6123$

$-0.7253$

$-0.5>33$

$-0.5374$

$-0.7737$

$-0.3471$

$-0.5531$

$-1.05 \leqslant 0$

$-0.9307$

$-1.1622$

$-1.0057$

$-1 \cdot 2.36$

$-1.0772$

$-1.7507$

$-1.1445$

$-1.4456$

$-1+\hat{c} \in \mathbb{0}$

$-1 . \Xi こ \vdots 1$
VELOC.

$A C C$.

$-1.0762$

$-1.0 \approx 45$

$-2 \cdot 13=5$

$-2.1680$

$-3.1353$

$-3.24=1$

$-4.0756$

$-4.3155$

-4. 532

$-5.3735$

$-5 \cdot 6944$

$-6 \cdot 3=67$

$-6.5514$

$-7.3719$

- E. 5.53

$-5.2773$

$-7.3372$

$-9.0900$

$-7.6571$

$-5.7966$

$-7.2=34$

$-10.3407$

$-8.0212$

$-10.7317$

.8 .0561

$-10.0425$

$-9.0028$

$-10.5513$

-7.054 ?

$-10 \cdot 75 \equiv 7$

$-7.6,435$

$-10.4121$

$-7.3403$

-. \pm 566

$-5.552=$

$-=.133 \mathrm{f}$

$-6.47=4$

$-.2654$

$-5.7644$

$-7.1229$
$-107.2574$

$-102.447 \mathrm{~F}$

$-103.70 ?$ ?

$-105.305:$

-57. $5 \overline{15}$.

$-107.0307$

$-90.3353$

$-10 \in .670$ ?

$-81.3074$

$-104.4110$

$-71 \cdot 140^{\circ}$

$-100.5104$

$-60.3210$

$-54.55 E 0$

$-49.24 \equiv 1$

$-66.2207$

$-38.2544$

$-76.3122$

$-27 \cdot 52=4$

$-63.2574$

$-17.5048$

$-47.0417$

$-7.9510$

$-30.520=$

1. 0654

$-11.7523$

$=.6535$

7.9227

17.5710

$27.707^{\circ}$

26.1565

46.8502

34.4903

64.5328

$42.966=$

Q0.43.1?

51.6652

93.764 c

60.4352

104.3233 
F. Computer Program \#2

IUSE $\quad$ DARESE=5,TEME $=5, L I N S S=4.00$

1

C

C

c

C

c

C

c SEISNIE RE SPAOISE ELASTIC SHEAR SUILDIAG

IMPLIC:T REHL+:(A-レ, S-Z)

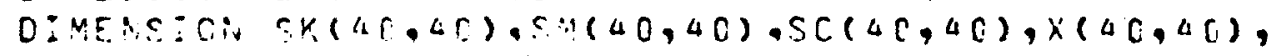

$10(14(46), U 5(40), U V(40), U A(40), S(40), 5: E E:(40)$

READ TIFUT TATE A:J INITIALIZE

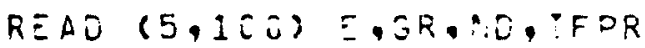
WRITE (F, 1 H G) GR, UD,IFDR

$10 C$ FOPMAT (2F1L.0.2T5)

DE $2:=1,110$

Cᄃ $2 \quad J=1 \cdot 3$

SU $(I \cdot J)=0.0$

$\operatorname{SC}(I, J)=0.0$

$x(I, J)=0.0$

$2 \operatorname{SK}(I, J)=0.0$

$\therefore \cup 1=: 00+1$

D) $7:=1 .: 17$

READ(5.110) SI,SL,SM(I,I)

HPITE(S,110)SI,SL,SM(I,I)

110 FCRMAT (ZF10.2.F10.C)

$S(I)=12 \cdot 0+E+S I / S L+J$

$S C(I, I)=S *(I, I)$

UD $(I)=0.0$

$7 \cdot U V(i)=\hat{U} \cdot 0$

$S(N O+1)=0.8$

DC 19 i $=1, \therefore 5$

IF(I.:- I.1) Gr TS 15

$S K(I, I-1)=-S(I)$

$S K(I-1, i)=-S(i)$

$1=\operatorname{SK}(I, j)=S(I)+5(I+1)$

C

c

C

c

c

DETEKNERE YATIJEAL FREGUEACEES AND MCEE SHAPES CALL UACEEI (SK,SC,Y,EIBEY,S,AD,IFPR)

RESPONSE US?HO MODAL SUEERPCSETEON

CALL YCEAL (AIE, EISE $: X, S C, G R, S N)$

ST IF

C

END

C.

SOLVE EIGE MFROELEN USIA!G JACCPT METHOD

SUPREUT:IE JAREEI (A,F,X,FIGV,L, N,IFPR)

IALIC:T IEAL*

OIMENSICN A $(40.40), E(4 \Gamma, 40), y(40,40), 5$ I UV $(40), C(40)$

IVITIALS? EISENVCLUF ANO EI ESNVECTSR MATFICES

ASMAX $=15$

RTCL $=1.0-12$

IOUT $=6$.

DO $10:=1$. 
c

c

c

c

c

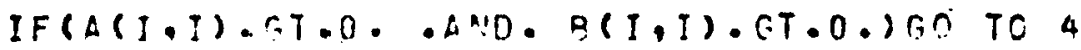

WRITE (IOLT Q E0.0)

STip

$4 \quad D(:)=L(I,:) / E(:, Z)$

10 EIGV(I) $=?(:)$

D) $30 \quad$ I $=1$.

O? $20 \quad J=1$.

$20 \times(I, J)=0$.

$30 \times([, I)=1$.

IF(H.F?.1) RETURY

IVITISLIZE SWEEP EEURTER AND EEGEY ITERATIOR.

NSWEEO $=0$

$N R=: \because-1$

$4 C$ NSWEEF=ASNECF+

IF (IFPR.EG I) URITE(ICUT.2000) M.S KEEF

CHECK IF PRESEPT EFF-OIAGSNAL ELENENT IS LARGE

$E P S=(.01+* 1.96 \equiv \equiv P)+2$

DO $210 \mathrm{~J}=I, \mathrm{~A}: \mathrm{R}$

$J u=u+1$

DO $210 k=J U: A$

EFTCLA $=(A(U, k) * A(J \cdot K)) /(\Delta(J, J) * A(K, K))$

EPT SL $\Xi=(\Xi(J, K)+\Xi(J \cdot K)) /(B(J \cdot U)+E(K \cdot K))$

IF (EPTOLA.LT.EPS).AND. (EPTCLE.LT.EPSS)EE TO 210

C

IF ZERE:AG ES RFQU:RES, CALCULATE THE RETATICA NATRIX ELEMEAT CA,CE

$A K K=A(K, K) * E(J, K)-E(K, K) * A(U, K)$

$A J J=A(J, J)+E(J, K)-E(J, J) \star A(J, K)$

$A E=A(J, J) * E(K, K)-\Delta(K, K) \star Q(J, J)$

CHECK $=(A E+S S+4+4 K K+A J J) / 4$.

IF $(C L E C K) E O, 60,50$

50 WRITE(ICUT, ZQ2C)

ST RF

6C SGCH=ESCRT (CHECK)

$01=A B / ? .+E \cap C H$

$D 2=4.8 / 2 \cdot-5.2 C H$

$D E N=01$

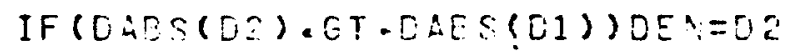

IF $(O E N): 0,70, \therefore 0$

$70 \quad C A=C$.

$C G=-A(U, K) / N(K, k)$

$C G=-A(U, K) / L(K, K)$

GC TC $: 0$

\&O CA $A K R / D E$.

$C G=-A J U / C E:$

GENERALITED ZRTAT:EN TO ZERO THE PRESENT OFF-CIAGCPAL ELENEAT

$3015(p-2) 100.190,100$

IOC $J=1=J+1$

JYI $=u-1$

$K P 1=K+1$

$K M_{1}=K-1$

$I=(J N 1-1) 130,110,110$

110 DO $120 \quad I=1, N 1$

$A J=A(I, J)$ 


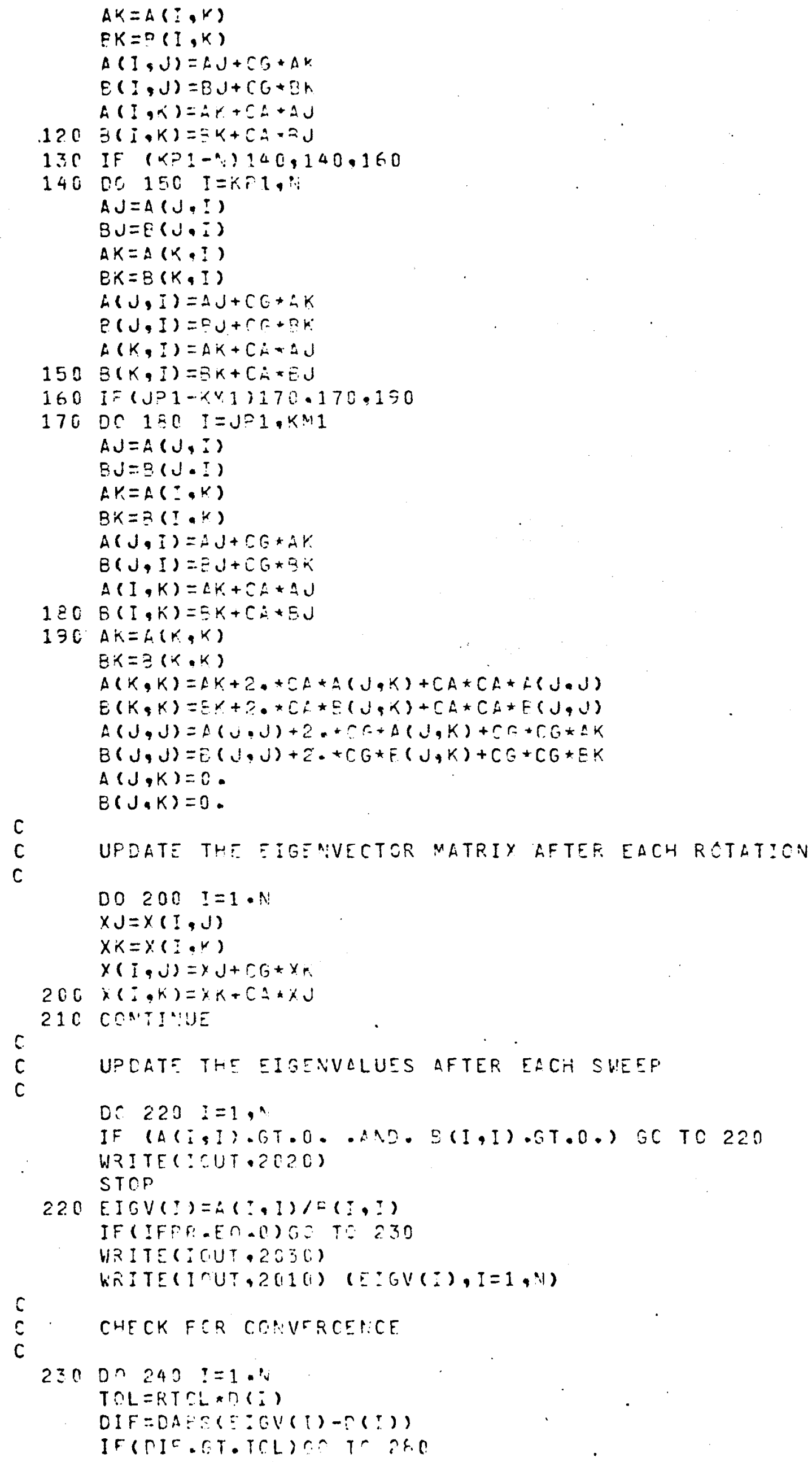

DC $220 \quad i=1$,

IF (A(I,I).GT.O. .AD. E(I,I).GT.0.) GC TC 220 WRITE (:EUT.2020)

STOP

220 EIGV $(I)=\dot{A}(I, I) /=(I, I)$

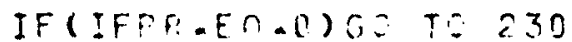

HRITE(ICUT. 203()

KRITE(IOUT, 2(11(i) (E:GV(i), I=1, M)

c

\section{CHECK FER COUVERCEIICE}

230 on $240 \quad:=1$.

$T O L=R T S L * \Pi(Z)$

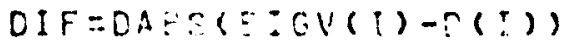

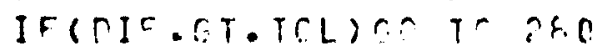


c

C CHECK ELL OFF-OIASCANAL ELENE:TS TO SEE IF ANCTHER SWEED IS C REQUIRED.

140 141

142

143

144

145

146

147

145

c 250 CCNTIRUE

C FILL OUT PCTTON TETANGLF CF RESULTANT MATEICES

149

150

151

152

153

154

155

156

c

c

c

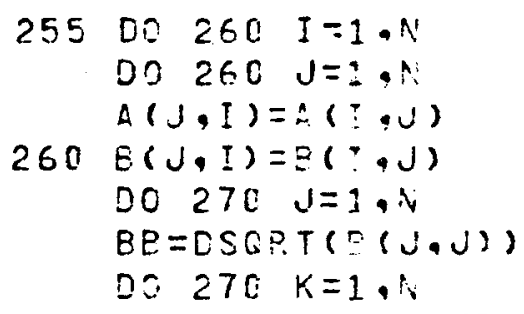

$270 x(K, J)=x(K, U) / E E$

UPDATE MATRIX AUD START NEW SWEEP, IF ALLCWED

WRITE $(6,1990)$

DC $1991 \quad L:=1, \therefore$

$19 \equiv 1$ NRITE $(6,2010)\left(X\left(L \sum-1 U\right), L J=1, P\right)$

1SSO FCRMAT (/10X, EE ZEENVECTCRS,/)

RETUR!

580 DS $\angle C C \quad I=3 . N$

$2 \div 0 D(I)=E: 0 V(:)$

IF (USWEED. LT ASSAX)GO TO 40

GO TO :aE

2000 FIRMAT( /,27HESLEEP AUMBER IN HJCCEI* $=, T 4)$

2010 F(ENATIIHE.SE14,5/)

2020 FORYAT (25HE\# ERFLR SOLUT:G STLP /

1 3OH MATRICES NOT FCSITVE DEFI:ITE)

2030 FORMAT(JEHRCURRENT ETGEVVALUES IN *JACCEI+ARE,1)

END

C

C

C

171

172

173

174

C

C STEMENT FUNCTISTS

RESFOASE LSING MOOAL SUFERPCSITICN METHOD

SUERC.UTIUE MAEAL(UD,EIEEM,X,F,GR,SM)

INPLIC:T IRFAL

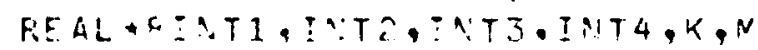

1 . UC $(40),=F(40), V 0(40), S A:(40,40)$

C

DINESSIC: EIGEP(40), X(40,40), X:S(40),F(40,40),F(40),T(40),Y(40,40)

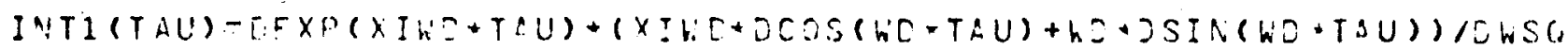

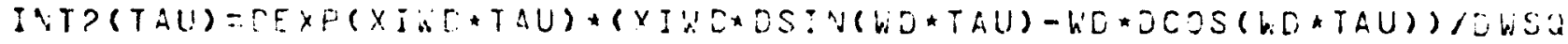

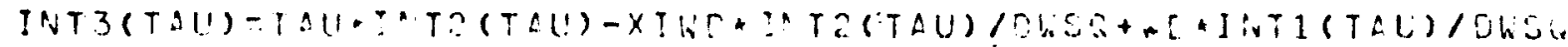


c

$N G=N D$

$I F(J R \cdot A E \bullet 0, V G=1$

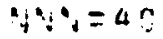

c

REAS(S,119) ПT, TYAY, (1.G(L),L=1.NG)

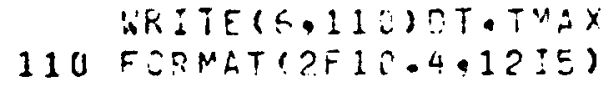

$0076 \quad I=1 \cdot \therefore N$

$F F(I)=? .0$

DS $76 \mathrm{~J}=1, \cdots 9$

$75 \cdot F(I, J)=0.0$

OS $77 \quad i \mathrm{~L}=1 \cdot 1.6$

NEQ $=$ NO (ID)

IF (YIEC.EO.0) 60 TO 77

REAC (F, 1:C) (T(L), P(L),L=1, AECG)

120 FORMAT (4FIT.2)

WRITE(E.1ZC) ( T (L), F (L),L=1, AEO)

$V T=T(N E Q) / C T$

IF (NT. GT.TVAX/CT) $\quad: T=T M \Delta X / \Pi T$

NTI $=N T+1$

$F F(1)=P(1)$

$A N A_{1}=0,3$

$I I=1$

Do $1 \equiv I=2, \cdot{ }^{\prime} T I$

$A I=I-1$

$T A=A I+D T$

IF(TA.GT.T (NEG)) GO TO 160

IF(TA.LE.T (II+1)) 60 TO

$A N_{1}=-T(I:+1)+T A-E T$

$I I=I I+I$

C $A N_{N}=A M S+D T$

$F F(I)=P(I T)+(=(I T+1)-O(I I))+A N /(T(I I+1)-T(I I))$

$F(I D, I)=F F(I)$

19 CCUTI:UE

160 CEYTINUE

77 CESTIUUE

214

215

216

217

218

213

220

221

DETER:IYE TI:UE ANO EQUIVALENT FORCES

c

$N T=T N \triangle X / ? T$

D? $17 \mathrm{~L}=1+\because \mathrm{A}$

$A L=L-1$

$T(L)=T(1)+A L+D T$

IF (GR.EO.O.) G: TO 17

CO 1 I $: D=1$ : $: D$

18. $F(I C, L:=-F F(L) * \operatorname{SN}(T 2, I D)$

17 SONTI:U:

C.

c

READ JAMPI:G RATIZS AND SET IIITIAL VALUES

RELO(F, 1CC) (XIS(L),L=1, M!C)

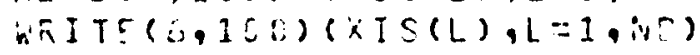

C

100 FQR $\because A T(\leq F I 0.3)$

c

WRITE HEACINGS

WRitr $(6,7$ CO)

700 FCFNATGIHI GX, MEZSMIC RESPCAST CIF ELASTIC SHEAR BUILE:NGM,

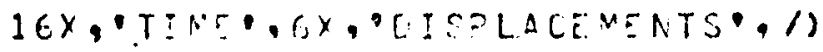
$\because T 1=V T+1$ 


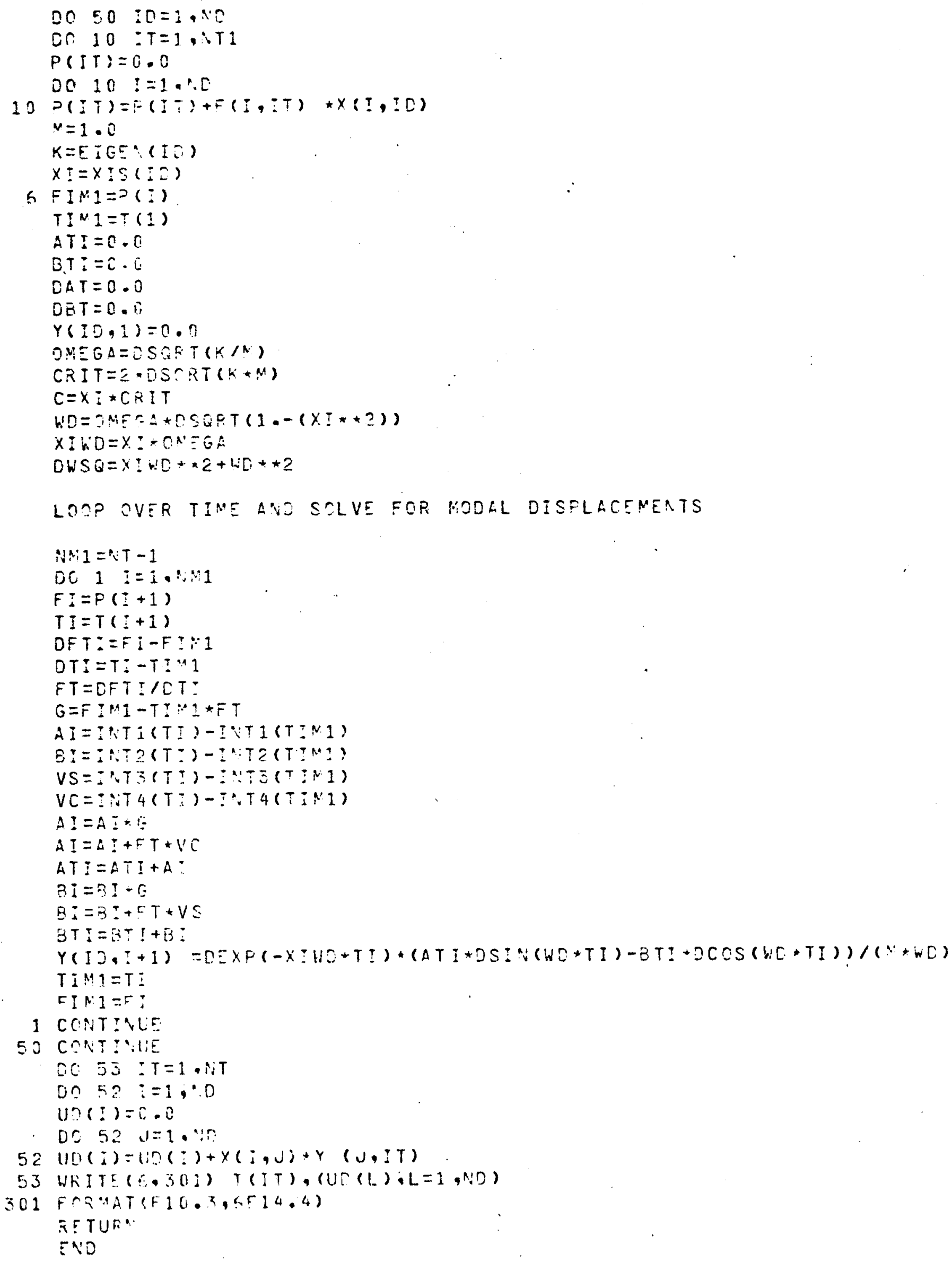




\section{ERROR INVESTIGATION DUE TO STATIC CONDENSATION}

Due to different loading conditions, and changes in geometry; it is sometimes necessary to divide the structure into a large number of elements. When the elements of the entire structure are assembled, the number of unknown displacements, or in dynamical terms, the number of degrees-of-freedom become very large. Therefore, the stiffness, the mass and the damping matrices become very large.

In such cases the solution of the eigenproblem to determine natural frequencies and mode shapes will be difficult and tedious. For this reason it is convenient to reduce the size of matrices in order to make the solution easier and manageable.

\section{A. Static Condensation}

A practical method of accomplishing the reduction of these matrices is to identify those degrees-of-freedom to be reduced as dependent coordinates and to express them in terms of the remaining independent degrees-of-freedom. The relation between the dependent and independent degrees-of-freedom is found by establishing the static relation between them, hence, the name static condensation method. This relation provides the means to reduce the stiffness matrix.

In order to reduce the mass and the damping matrices, it is assumed that the same static relation between dependent and independent degrees-of-freedom remains valid in the dynamic problem. Hence the same transformation based on static condensation for the reduction of the stiffness matrix is also used in reducing the mass and damping matrices. 
In general this method of reducing the dynamic problem is not exact and introduces errors in the results. The magnitude of these errors depends on the relative numbers of degrees-of-freedom reduced as well as on the specific selection of these degrees-of-freedom for a given structure. No error is introduced in reducing massless degrees-of-freedom, that is, degrees-of-freedom for which there is no mass allocated. The procedure of static condensation also is used in static problems to eliminate unwanted degrees-of-freedom such as the internal degrees-of-freedom of an element used with the finite element method of analysis. Initially the stiffness matrix is represented by a partition matrix as follows:

$$
\left[\begin{array}{c:c}
K p p & K p q \\
\hdashline K q p & K q q
\end{array}\right]\left[\begin{array}{l}
\{x p\} \\
\{x q\}
\end{array}\right]=\left[\begin{array}{l}
\{0\} \\
\{F q\}
\end{array}\right]
$$

which can be reduced or condensed by using the gauss elimination for the first $p$ unknown displacement. At this stage of the elimination process, the stiffness equation for the structure may be arranged in partition matrices as follows:

$$
\left[\begin{array}{cc}
{[I]} & -[\bar{T}] \\
0 & {[\bar{K}]}
\end{array}\right]\left[\begin{array}{l}
\left\{x_{p}\right\} \\
\left\{x_{q}\right\}
\end{array}\right]=\left[\begin{array}{l}
\{0\} \\
\left\{F_{q}\right\}
\end{array}\right]
$$

where $\left\{x_{p}\right\}$ is the vector corresponding to the $p$ degrees-of-freedom to be reduced and $\left\{x_{p}\right\}$ the vector corresponding to the remaining $q$ independent degrees of freedom. It should be noted that in (62) it was assumed that the external forces were zero at the dependent degree-of-freedom $\left\{x_{\rho}\right\}$. Equation (62) is equivalent to the following relations: 


$$
\begin{aligned}
& \left\{x_{p}\right\}=[\bar{T}]\left\{x_{q}\right\}, \\
& {[\bar{k}]\left\{x_{q}\right\}=\left[F_{q}\right] .}
\end{aligned}
$$

Equation (63) which expresses the static relation between coordinates $\left\{x_{p}\right\}$ and $\left\{x_{q}\right\}$ may also be written as

$$
\left[\begin{array}{c}
\left\{x_{p}\right\} \\
\left\{x_{q}\right\}
\end{array}\right]=\left[\begin{array}{l}
{[\bar{T}]} \\
{[I]}
\end{array}\right]\left\{x_{q}\right\}
$$

or

$$
\{x\}=[T]\left\{x_{q}\right\}
$$

where

$$
\{x\}=\left[\begin{array}{l}
\left\{x_{p}\right\} \\
\left\{x_{q}\right\}
\end{array}\right], \quad[T]=\left[\begin{array}{l}
{[T]} \\
{[I]}
\end{array}\right]
$$

Equation (64) which establishes the relation between coordinates $\left\{x_{q}\right\}$ and forces $\left\{F_{q}\right\}$ is the reduced stiffness equation and $[\bar{K}]$ the reduced stiffness matrix of the system, which may also be expressed as a transformation of the system stiffness matrix $[K]$ as

$$
[\bar{K}]=[T]^{T}[K][T]
$$


B. Static Condensation Applied to Dynamic Problems

In a previous section a case was considered in which the discretization of the mass has left a number of massless degrees-offreedom. For this case it is only necessary to condense the stiffness matrix and delete from the mass matrix the rows and columns corresponding to the massless degrees-of-freedom. In this case the methods used do not alter the original problem, thus the results are equivalent eigenproblems.

In cases when the discretization process has allocated mass to the system, the procedure commonly used is to apply the transformation shown in equation (68) not only to the stiffness matrix, but also to the mass and to the damping matrix of the system, analytically that is:

$$
[\bar{M}]=[T]^{T}[M][T]
$$

and the reduced damping matrix is

$$
[\bar{C}]=[T]^{T}[C][T]
$$

where the transformation matrix [T] is defined in (67). The justification of the mass and damping matrices reduction is shown as follows:

$$
\begin{gathered}
V=1 / 2\{x\}^{\top}[K]\{x\} \\
K E_{0} E_{0}=1 / 2\{\dot{x}\}^{\top}[M]\{\dot{x}\}
\end{gathered}
$$

where $V$ is the potential energy and the kinetic energy is represented 
by K.E. in equations (71) and (72) respectively。

Analogously, the work $\delta w_{d}$ done by the damping forces $\left.F_{d}=[C] \dot{x}\right]$ corresponding to displacements $\{\delta x\}$ may be expressed as:

$$
\delta w_{d}=\{\delta x\}^{\top}[C]\{\dot{x}\}
$$

By using the transformation (67) in equations (71), (72) and (73) gives the following results

$$
\begin{gathered}
v=1 / 2\left\{x_{q}\right\}^{T}[T]^{T}[K][T]\left\{x_{q}\right\} \\
K_{0} E_{0}=1 / 2\left\{\dot{x}_{q}\right\}^{T}[T]^{T}[M][T]\left\{\dot{x}_{q}\right\} \\
\delta w_{d}=\left\{\delta x_{q}\right\}^{T}[T]^{T}[C][T]\{\dot{x}\}
\end{gathered}
$$

The respective substitution of $[K],[\bar{M}]$ and $[\bar{C}]$ from (68), (69) and (70) for the product of the three matrices in (74), (75) and (76) yields:

$$
\begin{gathered}
V=1 / 2\left\{x_{q}\right\}^{\top}[K]\left\{x_{q}\right\} \\
K . E .=1 / 2\left\{\dot{x}_{q}\right\}^{T}[M]\left\{\dot{x}_{q}\right\} \\
\delta w_{d}=\left\{\delta x_{\dot{q}}\right\}[\bar{C}]\left\{\dot{x}_{q}\right\}
\end{gathered}
$$

These last three expressions represent the potential, the kinetic energy and the virtual work of the damping forces in terms of independent coordinates $\left\{x_{p}\right\}$. 


\section{Numerical Example}

To illustrate the theory, consider a three degree-of-freedom shear building shown in Figure 7, and find the natural frequencies and

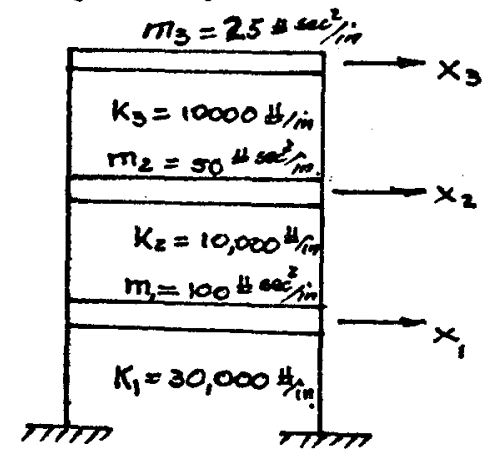

FIGURE 7.- Shear Building of Numerical Example

modal shapes; also condense one degree-of-freedom and compare the resulting values obtained for natural frequencies and mode shapes.

The equation of motion is given as free vibration in the following form:

$$
[M]\{\ddot{x}\}+[K]\{x\}=[0]
$$

Substituting the corresponding numerical values in this equation yields

$$
\left[\begin{array}{ccc}
100 & 0 & 0 \\
0 & 50 & 0 \\
0 & 0 & 25
\end{array}\right]\left[\begin{array}{l}
x_{1} \\
x_{2} \\
x_{3}
\end{array}\right]+10^{3}\left[\begin{array}{rrr}
40 & -10 & 0 \\
-10 & 20 & -10 \\
0 & -10 & 10
\end{array}\right]\left[\begin{array}{l}
x_{1} \\
x_{2} \\
x_{3}
\end{array}\right]=\left[\begin{array}{l}
0 \\
0 \\
0
\end{array}\right]
$$

assuming a solution $x_{j}=a_{i}$ sin $\omega t$, and substituting into the equation of motion yields, 


$$
\left[\begin{array}{ccc}
40,000-100 \omega^{2} & -10,000 & 0 \\
-10,000 & 20,000-50 \omega^{2} & 10,000 \\
0 & 10,000 & 10,000-25 \omega^{2}
\end{array}\right]\left[\begin{array}{l}
a_{1} \\
a_{2} \\
a_{3}
\end{array}\right]=\left[\begin{array}{l}
0 \\
0 \\
0
\end{array}\right]
$$

from which the characteristic determinant of the system can easity be deducted, such as

$$
\left|\begin{array}{ccc}
40,000-100 \omega^{2} & -10,000 & 0 \\
-10,000 & 20,000-50 \omega^{2} & 10,000 \\
0 & 10,000 & 10,000-25 \omega^{2}
\end{array}\right|=0
$$

expanding the determinant and solving gives

$$
\begin{aligned}
& \omega_{1}^{2}=84.64 \mathrm{rad} / \mathrm{sec} \\
& \omega_{2}^{2}=400 \\
& \omega_{3}^{2}=536
\end{aligned}
$$

The natural frequencies are calculated by $f=\omega / 2 \pi$, so that

$$
\begin{aligned}
& f_{1}=1.464 \text { CPS } \\
& f_{2}=3.183 \\
& f_{3}=3.685
\end{aligned}
$$

The modal shapes are determined by substituting each value of natural frequencies into equation (a) deleting one of the equations and solving the remaining two equations for two of the unknowns in terms of the 
third unknown, setting the unknown equal to one. Performing the operation gives,

$$
\begin{array}{lll}
a_{11}=1.00 & a_{12}=1.00 & a_{13}=1.00 \\
a_{21}=3.18 & a_{22}=0 & a_{23}=-2.88 \\
a_{31}=4.00 & a_{32}=-1.00 & a_{33}=4.00
\end{array}
$$

Since the stiffness for this structure is

$$
\left[\begin{array}{ccc}
40,000 & -10,000 & 0 \\
-10,000 & 20,000 & -10,000 \\
0 & -10,000 & 10,000
\end{array}\right]
$$

By the use of gauss elimination of the first unknown gives

$$
\left[\begin{array}{ccc}
1 & -0.25 & 0 \\
0 & 17,500 & -10,000 \\
0 & -10,000 & 10,000
\end{array}\right]
$$

Comparing (c) with (62) indicates that

$$
\begin{aligned}
& {[\bar{T}]=\left[\begin{array}{lc}
0.25 & 0
\end{array}\right]} \\
& {[\bar{K}]=\left[\begin{array}{cr}
17,500 & -10,000 \\
-10,000 & 10,000
\end{array}\right]}
\end{aligned}
$$

also from (67) 


$$
[T]=\left[\begin{array}{ll}
0.25 & 0 \\
1 & 0 \\
0 & 1
\end{array}\right]
$$

The condensed mass matrix is calculated by substituting matrix [T] and its transpose from (e) into equation (69).

$$
[\bar{M}]=\left[\begin{array}{lll}
0.25 & 1 & 0 \\
0 & 0 & 1
\end{array}\right]\left[\begin{array}{rrr}
100 & 0 & 0 \\
0 & 50 & 0 \\
0 & 0 & 25
\end{array}\right]\left[\begin{array}{ll}
0.25 & 0 \\
1 & 0 \\
0 & 1
\end{array}\right]
$$

which results in

$$
[\bar{M}]=\left[\begin{array}{cc}
56.25 & 0 \\
0 & 25
\end{array}\right]
$$

Substituting the reduced stiffness and reducing mass into the equation of motion gives

$$
\left[\begin{array}{cr}
56.25 & 0 \\
0 & 25
\end{array}\right]\left[\begin{array}{l}
\ddot{x}_{2} \\
\ddot{x}_{3}
\end{array}\right]+\left[\begin{array}{rr}
17,500 & -10,000 \\
-10,000 & 10,000
\end{array}\right]\left[\begin{array}{l}
x_{2} \\
x_{3}
\end{array}\right]=\left[\begin{array}{l}
0 \\
0
\end{array}\right]
$$

The natural frequencies and mode shapes are then determined by solving the eigenvalue problem.

$$
\left[\begin{array}{cc}
17,500-56.25 \omega^{2} & -10,000 \\
-10,000 & 10,000-25 \omega^{2}
\end{array}\right]\left[\begin{array}{l}
a_{2} \\
a_{3}
\end{array}\right]=\left[\begin{array}{l}
0 \\
0
\end{array}\right]
$$


equating the characteristic determinant to zero yields

$$
\left|\begin{array}{cc}
17,500-56.25 \omega^{2} & -10,000 \\
-10,000 & 10,000-25 \omega^{2}
\end{array}\right|=0
$$

expanding the determinant and solving for the natural frequencies gives

$$
\begin{aligned}
& \omega_{1}=9.2304 \mathrm{rad} / \mathrm{sec} \\
& \omega_{2}=25.018
\end{aligned}
$$

Then

$$
\begin{aligned}
& f_{1}=\frac{9.2304}{2 \pi}=1.47 c . \mathrm{S} \\
& f_{2}=\frac{25.018}{2 \pi}=3.98
\end{aligned}
$$

The corresponding mode shapes are obtained by substituting the frequencies into equation ( $f$ ) gives,

$$
\begin{array}{ll}
a_{21}=1 & a_{22}=1 \\
a_{31}=1.27 & a_{32}=1.77
\end{array}
$$

For this system of only three degrees-of-freedom, the reduction of one coordinate gives results that compare well only for the first mode. Experiencing with different numbers of degrees-of-freedom, it is clear that the condensation process results in an eigenproblem, which provides 
only about half of its natural frequencies and modal shapes within acceptable approximate values.

\section{Computer Program For Investigation of Error}

This program to investigate the error due to static condensation, eliminates rows or degrees-of-freedom by using a subroutine program called CONDE. This subroutine calculates the reduced stiffness matrix $[\bar{K}]$, the reduced mass matrix $[\bar{M}]$, and the transformation matrix $[\mathrm{T}]$; with these reduced values, the program proceeds to solve for the natural frequencies and modal shapes, giving enough values to compare with the results of a non reduced system.

The subroutine CONDE, in order to perform the condensation of degrees-of-freedom uses the following variables.

\begin{tabular}{lcl}
\hline Variable & Symbot in Thesis & \multicolumn{1}{c}{ Description } \\
\hline ND & $N$ & $\begin{array}{l}\text { Total number of degrees-of- } \\
\text { freed om }\end{array}$ \\
NCR & $P$ & $\begin{array}{l}\text { Number of dependent modal } \\
\text { coordinates }\end{array}$ \\
NL & ND-NCR & $\begin{array}{l}\text { Number of degrees-of-freedom } \\
\text { minus number of dependent coordi- } \\
\text { nates }\end{array}$ \\
$S M(I, U)$ & {$[M]$} & Mass matrix \\
$S K(I, J)$ & {$[K]$} & Stiffness matrix \\
$T(I, U)$ & {$[T]$} & Transformation matrix
\end{tabular}

The elimination of degrees-of-freedom can be done in an organized fashion. For this purpose this thes is introduces the subroutine ORDER. Therefore the programer has the freedom to choose the desired row to el iminate this and proceed to solve for the remaining degrees-of-freedom. 
After experimenting with this program, it is obvious that the static condensation approach provides only about half of its eigenvalues and eigenvectors within acceptable approximate values.

E. Computer Program \#3 
C

EVALUATION OF ERROR FOR MULTI - DEGREE OF FREECJM STRUCTURE

IMPLICIT REAL $2(A-H, O-2)$

DIMENSION SM $(50,50), \operatorname{SK}(50,50), \operatorname{SC}(50,50), T(50,50), T T(50), E I G V(50)$

READ INPUT DATA AND INITIALIZE

REAO(5,100) ND,IF?R

WRITE(6,10C) ND, IFPR

100 FCRMAT (2I10)

$N L=N O$

$L \cap C=1$

NM1 $=$ NO -1

DO $2 I=1, N D$

DO $2 J=1, N D$

$\operatorname{SM}(I, J)=0.0$

$\operatorname{SM}(I, I)=1 \cdot 0$

$S C(I, J)=0.0$

$S C(I, I)=1 \cdot 0$

$2 \operatorname{SK}(I, J)=0.0$

DO $1 \equiv I=1, N D$

IF (I.EQ.1) GO TO 19

$S K(I, I-1)=-12$.

$S K(I-1, I)=-12$.

$17 S K(I, I)=24$.

$S K(N D, N D)=12$.

DO $30 \quad I C=1$, ND

IF (IC.EO.1) GO TO 20

$N L=N D-I C+1$

$N C R=N D-N L$

CALL CCNOE (NC, NCR,LOC,SK,SM,SC,T)

QO CALL JACOBI (SK,SC,T,EIGV,TT,NL,IFPR)

SO CONTINUE

STOP

END

C

STATIC CONDENSATION OF STIFFNESS AND MASS MATRICES

C

C

SUBROUTINE CONDE (ND,NCR,LOC,SK,SM,SC,T)

IMPLIC:T REAL $\$(A-H, O-Z)$

DIMENSION SK $(50,50), \operatorname{SM}(50,50), T(50,50), T T(50), \operatorname{SC}(50,50)$

34

CALCULATE THE REDUCED STIFFNESS MATRIK AND THE TRANSFCRMATION MATE

202 FCIRMAT $(6,202) \mathrm{K}$

$N L=N D-N C R$

DO \& $K=1, N C R$

IF $(D A B S(S K(K, K)) \cdot G T \cdot 1 \cdot D-10) \quad 60$ TO 5

PIVOT TOO SMALL, IIOJ

GO TO 99

$5 K P 1=K+1$

$D G 6 \quad J=K P 1, N D$

$6 S K(K, J)=S K(K, J) / S K(K, K)$

$S K(K, K)=1$.

DO $9 I=1, N D$

IF $(I . E Q \cdot K \cdot O R \cdot S K(I, K) \cdot E Q .0)$ GOTO 9

D? $8 \mathrm{~J}=K \mathrm{KP}_{1}$. NO

a $S K(I, J)=S K(I, J)-S K(I, K) \star S K(K, U)$

$S K(I, K)=0.0$

a CONTINUE 


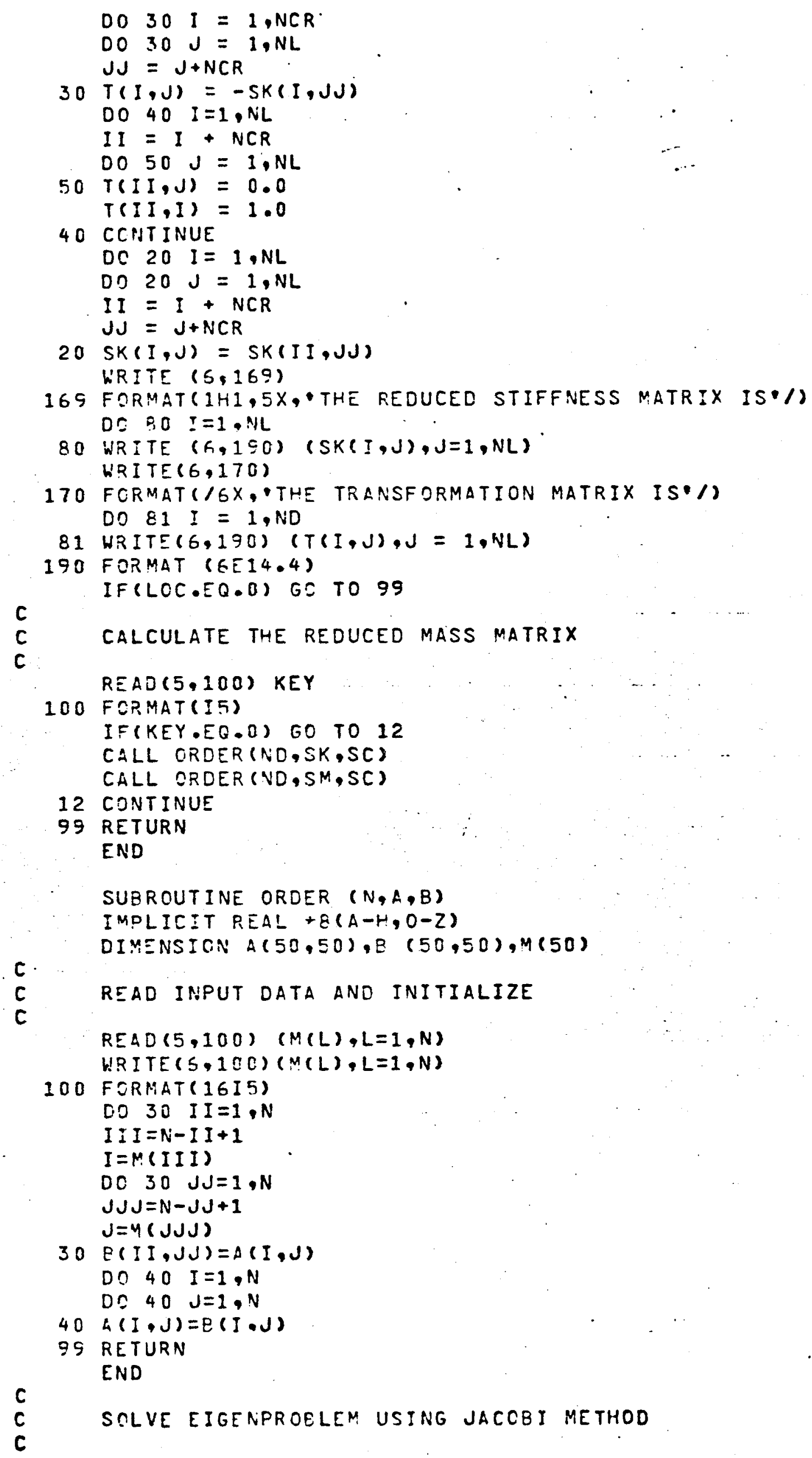


IMPLICIT REAL*C $(A-H, O-Z)$

C

C

C

C

$30 \times(I, I)=1$.

IF (N.EQ.1) RETURN

$4 D(I)=A(I, I) / B(I, I)$

$10 E I G V(I)=D(I)$

DO $30 \quad I=1, N$

$0020 \mathrm{~J}=1, \mathrm{~N}$

NSMAX $=15$

RTCL $=1 \cdot D-12$

D? $10 \quad I=1, N$

IF $(A(I, I), G T \cdot O$. A AND. B $(I, I), G T \cdot O, O) G O$ TO 4

WRITE (IOUT, 2020)

INITIALIZE SHEEP COUNTER AND EEGIN ITERATION

NSHEEP $=0$

$N R=N-1$

40 NSWEEP = NSWEEP+1

IF (IFPR . EQ.1)WRITE(IOUT, 2000$)$ NSWEEP

c

C

C

c

c

c

CHECK IF PRESENT OFF-DIAGCNAL ELEMENT IS LARGE

EPS $=(.01 *$ NSWEEP $) * 2$

DO $210 J=1, N R$

$J J=J+1$

DO $210 \quad K=J J, N$

EPTOLA $=(A(U, K) * A(J, K)) /(A(J, J) * A(K, K))$

EPTOLB $=(B(J, K) * B(J, K)) /(B(J, J) * 3(K, K))$

IF( (EPTOLA.LT.EPS).AND. (EFTOLE.LT.EPS)) GO TO 210

IF ZERCINE IS REQUIRED,CALCULATE THE ROTATION MATRIX ELEMENT CA,C

$A K K=A(K, K) * E(J, K)-E(K, K) * A(J, K)$

$A J J=A(U, J) * B(J, K)-E(J, J) * A(J, K)$

$A B=A(J, J) * P(K, K)-A(K, K) * B(J, J)$

$C H E C K=(\triangle B \star \Delta B+4 * \star A K K \star A J J) / 4$.

IF $(2 H E C K) 50,60,60$

50 WRITE(IOUT,2020)

STCP

60 SQCH =DSQRT (CHECK)

$D 1=A B / 2 \bullet+S Q C H$

$D 2=A B / 2 \bullet-S Q C H$

$D E N=01$

IF ( JA3S (D2) . GT.DABS(D1)) DEN $=02$

IF (DEN) $60,70,80$

$70 C A=0$.

$C G=-A(J, K) / A(K, K)$

$C G=-A(J, K) / A(K, K)$

GO TO $\subseteq 0$

8. $C A=A K K / D E N$

$C G=-A J J / D E N$ 
90 IF $(N-2) 100 \cdot 130.100$

100 JP $1=J+1$

$J M 1=J-1$

$K P 1=K+1$

$K M 1=K-1$

151

152

153

154

155

156

157

158

159

160

161

162

163

164

165

166

167

168

169

170

171

172

173

174

175

176

177

178

179

180

181

182

183

184

185

186

187

188

189

190

C

C

C

$11000120 \quad I=1, J M 1$

$A J=A(I, J)$

$B J=B(I, J)$

$A K=A(I, K)$

$B K=B(I, K)$

$A(I, U)=A J+C G \star A K$

$B(I, J)=B J+C G \star B K$

$A(I, K)=A K+C A \star A J$

$120 B(I, K)=B K+C A * B J$

130 IF $(K P 1-N) 140,140,160$

$14000150 \quad I=K P 1, N$

$A J=A(J, I)$

$B J=B(J, I)$

$A K=A(K, I)$

$B K=B(K, I)$

$A(J, I)=A J+C G \star A K$

$B(J, I)=B J+C G \star B K$

$A(K, I)=A K+C A * A J$

$150 \quad B(K, I)=B K+C A * B J$

160 IF $(J P 1-K M 1) 170,170,190$

170 DO $180 \quad I=J P I, K M 1$

$A J=A(J, I)$

$B J=B(J, I)$

$A K=A(I, K)$

$B K=B(I, K)$

$A(J, I)=A J+C G \star A K$

$B(J, I)=B J+C G \star B K$

$A(I, K)=A K+C A \star A J$

$130 B(I, K)=B K+C A * B J$

$130 \quad A K=A(K, K)$

$B K=B(K, K)$

$A(K, K)=A K+2 * A A \star A(J, K)+C A \star C A \star A(J, J)$

$B(K, K)=B K+2 . * C A * B(J, K)+C A * C A * B(J, J)$

$A(J, J)=A(J, J)+2 *$ J $(G \star A(J, K)+C G \star C G \star A K$

$B(J, J)=B(J, J)+2 * \star 2 G \star 3(J, K)+C G \star C G \star B K$

$A(J, K)=0$.

$B(J, K)=0$.

UPDATE THE EIGENVECTOR MATRIX AFTEF EACH ROTATION

$00200 \quad I=1, N$

$X J=X(I, J)$

$X K=X(I, K)$

$x(I, J)=x J+C G \star x K$

$200 x(I, K)=X K+C A \star X J$

C

210 CONTINUE

C

C

UPDATE THE EIGENVALUES AFTER EACH SWEEP

DO $220 \quad I=1, N$

IF $(A(I, I) \cdot G T \cdot 0 .-A N D \cdot B(I, I) \cdot G T \cdot 0$.$) GO TO 220$

WRITE(IOUT, 2020)

STOP

$220 \operatorname{EIGV}(I)=A(I, I) / B(I, I)$ 
IF (IFPR EEQ.0)GO TO 230

WR I TE (IOUT, 2030$)$

204

205

206

207

208

209

210

211

212

213

214

215

215

217

218

219

220

221

222

223

224

225

226

227

228

229

230

231

232

233

234

235

236

237

c 250

WRITE(IOUT,2010) (EIGV(I),I=I,N)

$c$
$c$

C

\section{CONTINUE}

$23000240 \quad I=1, N$

$T O L=R T C L \star D(I)$

$D I F=C A B S(E I G V(I)-2(I))$

IF(DIF.GT.TOL)GO TO 280

c

CHECK ALL OFF-DIAGONAL ELEMENTS REQUIRED

C

$$
E P S=R T C L * \star 2
$$

DJ $250 \quad J=1, N R$

$J J=J+1$

DO $250 \mathrm{~K}=\mathrm{J}, \mathrm{N}$

EPSA $=(A(J, K) * A(J, K)) /(A(J, J) * A(K, K))$

$E P S E=(B(J, K) \star B(J, K)) /(E(J, J) \star B(K, K))$

IF ( (EPSA.LT.EPS) A ND. (EPSE:LT.EPS)) GO TO 250

GO TO 280

C FILL OUT BOTTOM TRIANGLE OF RESULTANT MATRICES

C AND SCALE EIGENVECTORS

C

$25500260 \quad I=1, N$

DO $260 \quad J=1, N$

$A(J, I)=A(I, J)$

$260 \quad B(J, I)=B(I, J)$

DO $270 \quad J=1, N$

$B B=D S Q R T(B(J, J))$

DO $270 \quad K=1, N$

$270 x(K, J)=x(K, J) / B B$

c

C

UFDATE MATRIX AND START NEW SHEEP, IF GLLOWED

C

WRITE $(6,2010)((X(L I, L J), L J=1, N), L I=1, N)$

RETURN

280 DO $290 \quad I=1, N$

$290 D(I)=E I G V(I)$

IF (NSWEEP.LT.NSMAX)GO TO 40

GO TO 255

2000 FORMAT $(/, 27 H D S W E E P$ NUMBER IN JACOEI $=, 14)$

2010 FCRMAT (IHC,3E20.12/)

2020 FORMAT (25HC * * ERROR SOLUTION STOP /

1 3OH MATRICES VOT POSITVE DEFINITE)

2030 FORMAT $(36$ HOCURRENT EIGENVALUES IN * JACCBI*ARE, $/ 1)$

END

P SENTRY

3

1

WEEP NUMBER IN *JACOSI* = 1

URRENT EIGENVALUES IN * JACOEI*ARE. 
SHEE? NUMEER IN J JACOBI* $=2$

CURRENT EIGENVALUES IN $\star J A C C B I * A R E$,

$0.3896375260570 \quad 02 \quad 0.186595002239002 \quad 0.2376747170490 .01$

SHEEP NUYBER IN *JACOBI* $=3$

CURRENT EIGENVALUES IN \#JACOBI*ARE,

$\begin{array}{lllllll}0.3856375524460 & 02 & 0.1965949759500 & 02 & 0.2376747170340 & 01\end{array}$

SHEEP NUMEER IN *JACOBI* $=4$

CURRENT EIGENVALUES IN *JACOBI*ARE,

$0.3836375524460 \quad 02 \quad 0.1865949758500 \quad 02 \quad 0.237674717034001$

SWEEP NUMBER IN * JACOBI* $=5$

CURRENT EIGENVALUES IN \#JACOBI*ARE,

$$
\begin{array}{cccccc}
0.3596375524460 & 02 & 0.1865949758500 & 02 & 0.2376747170340 & 01 \\
0.5910090485060 & 00 & 0.7369762271000 & 00 & 0.3279552776060 & 00 \\
-0.7369762291000 & 00 & 0.3279852776060 & 00 & 0.5910090485060 & 00 \\
0.3273352776060 & 00 & -0.5910050485060 & 00 & 0.7369762291000 & 00
\end{array}
$$


- THE REDUCED STIFFNESS MATRIX IS

1

$0.5472002 \quad-0.23570-36$

$-0.23670-35 \quad 0.4504001$

THE TRANSFCRMATION MATRIX IS

$\begin{array}{ccccc}0.16570-14 & 0.19920-23 \\ 0.10000 & 01 & 0.00000 & 00 \\ 0.00000 & 00 & 0.10000 & 01 \\ 3 . & 2 & 1 & & \\ 3 & 2 & 1 & \end{array}$

SWEE 2 NUMEER IN * JACOBI* $=1$ CURRENT EIGENVALUES IN *JACOBI*ARE,

$0.6471579825440 \quad 02 \quad 0.4504103058190 \quad 01$

$0.1000000000000010 .000000000000000 \quad 0.000000000000000$

0.100000000000001

THE REDUCED STIFFNESS MATRIX IS

0.4504001

THE TRANSFORMATION MATRIX IS

$0.30630-25$

$0.63650-37$

0.1000001 


\section{ANALYSIS OF NONLINEAR STRUCTURAL RESPONSE}

In the analysis of linear structures subjected to any arbitrary dynamic loadings, the Duhamel integral provides the most convenient approach for the solution of the systems. However, it must be emphasized that the Principle of Superposition that was employed in the derivation of Duhamel integral, can only be used with linear systems, that is, systems for which the properties remain constant during the response. There are however, physical situations for which this linear model does not represent adequately the dynamic characteristics of the structure, such as the response of a building to an earthquake motion severe enough to cause structural damages. Consequently, it is necessary to develop another method of analys is suitable to use with nonlinear systems.

A. Incremental Equation of Equilibrium

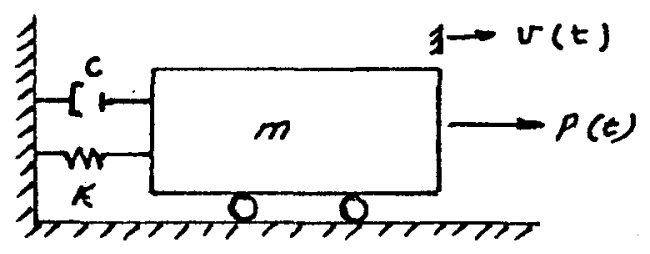

FIGURE 8(a) - Mathematical Model for Non7inear Structural Response

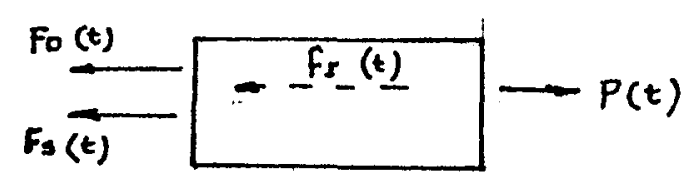

FIGURE $8(b)$ - Free Body Diagram 
The structure to be considered in this section is a single degreeof-freedom shown in Figure 8(a). The dynamic equilibrium in the system is established by equating to zero the forces acting on the mass of the system indicated in Figure $8(\mathrm{~b})$. This summation at any instant of time $t$ in equilibrium of forces acting on the mass $m$ requires

$$
F_{I}(t)+F_{D}(t)+F_{S}(t)=F(t)
$$

or

$$
m \ddot{x}\left(t_{i}\right)+c_{i} \dot{x}\left(t_{i}\right)+k_{i} x\left(t_{j}\right)=F\left(t_{i}\right)
$$

In equation $(80) \mathrm{b}$ the coefficient $C_{j}$ and $K_{j}$ are calculated for values of velocity and displacement at time $t_{i}$.

For an increment $\Delta t$ later the equation (80)a takes the following form:

$$
F_{I}(t+\Delta t)+F_{D}(t+\Delta t)+F_{S}(t+\Delta t)=F(t+\Delta t)
$$

and equation (80)b takes the form of

$$
m \ddot{x}\left(t_{i}+\Delta t\right)+c_{i} \dot{x}\left(t_{i}+\Delta t\right)+K_{i} x\left(t_{i}+\Delta t\right)=F\left(t_{i}+\Delta t\right)
$$

Subtracting (81)b from (80)b gives the following convenient form of differential equation in terms of increments, namely

$$
\Delta F_{I}(t)+\Delta F_{D}(t)+\Delta F_{S}(t)=\Delta F(t)
$$


or

$$
m \Delta \ddot{x}_{j}+C_{j} \Delta \dot{x}_{i}+K_{j} \Delta x_{j}=\Delta F_{i}
$$

where the incremental forces in (82)a may be expressed as follows:

$$
\begin{aligned}
\Delta F_{I}(t)=F_{I}(t+\Delta t)-F_{I}(t) & (a) \\
\Delta F_{D}(t)=F_{D}(t+\Delta t)-F_{D}(t) & (b) \\
\Delta F_{S}(t)=F_{S}(t+\Delta t)-F_{S}(t) & (c) \\
\Delta F(t)=F(t+\Delta t)-F(t) & \text { (d) }
\end{aligned}
$$

and from equation (82)b the incremental displacement, velocity, acceleration and force are

$$
\begin{aligned}
& \cdot \Delta x_{i}=x\left(t_{j}+\Delta t\right)-x\left(t_{j}\right) \quad(a) \\
& \Delta \dot{x}_{j}=\dot{x}\left(t_{i}+\Delta t\right)-\dot{x}\left(t_{j}\right) \quad \text { (b) } \\
& \Delta \ddot{x}_{i}=\ddot{x}\left(t_{i}+\Delta t\right)-\ddot{x}\left(t_{j}\right) \quad \text { (c) } \\
& \Delta F_{j}=F\left(t_{j}+\Delta t\right)-\Delta F_{j}
\end{aligned}
$$

The general nonlinear characteristics of spring and damping forces are shown in Figure $(9) a, b$.

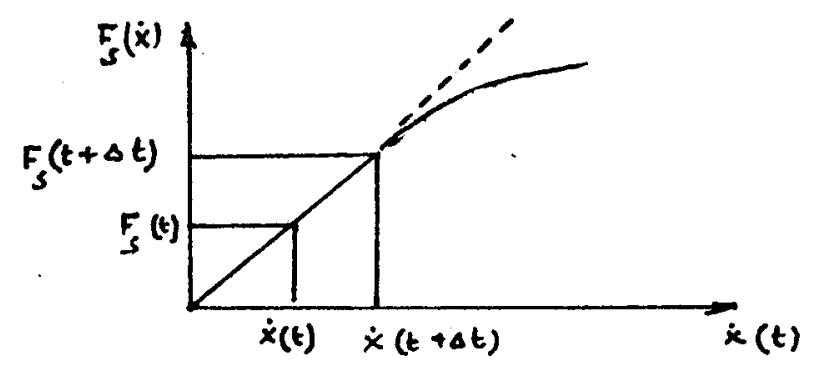

FIGURE 9(a) - Nonl inear Characteristic of Spring 


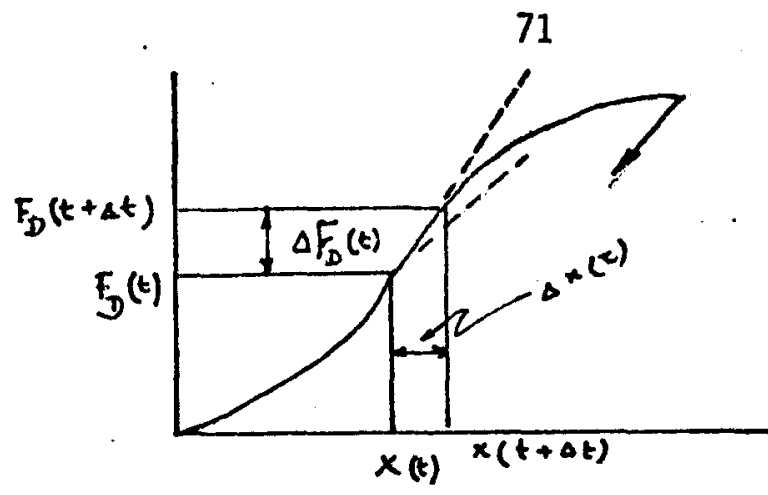

FIGURE 9(b) - Nonlinear Characteristic of Damping Force

In practice, the secant slope indicated could be evaluated only by iteration because the velocity and displacement at the end of the time increment depends on the damping and stiffness properties, corresponding to the velocity and displacement existing during the time interval. For this reason the tangent slope defined at the beginning of the time intervals are used instead.

$$
C(t)=\frac{d F_{D}}{d x}, \quad K(t)=\frac{d F_{S}}{d x}
$$

Among the methods available for the solution of equation (82)b, the most effective is the step by step integration method. In this method, the response is calculated at successive increments of time, usually taken at equal time intervals. At the beginning of each interval, the condition of dynamic equilibrium is established. Then the response of a time increment $\Delta t$ is evaluated approximately on the basis that the coefficients $K(x)$ and $C(x)$ remain constant during the interval $\Delta t$. The nonlinear characteristic of these coefficients are found at the beginning of each time increment. The response is then obtained using the displacement and velocity calculated at the end of the time interval as the initial condition for the next time step. 
There are several procedures available for performing the step by step integration of (82)b. Two of the most common used are the constant acceleration method. As may be expected the linear acceleration method will be presented here in detail.

B. Step By Step Integration (Linear Acceleration Method)

In this method, it is assumed that the acceleration may be expressed by a linear function of time during the time interval $\Delta t$. When the acceleration is assumed to be linear function of time the interval of time $t_{j}$ to $t_{j+1}=t_{j}+\Delta t$, then the acceleration should be expressed as

$$
\ddot{x}(t)=\ddot{x}_{i}+\frac{\Delta \ddot{x}_{j}}{\Delta t}\left(t-t_{j}\right)
$$

where $\Delta \ddot{x}_{i}=\ddot{x}\left(t_{j}+\Delta t\right)-\ddot{x}\left(t_{j}\right)$ as shown before; integrating (86) twice between the limits $t_{i}$ and $t$ yields

$$
\dot{x}(t)=\dot{x}_{i}+\ddot{x}\left(t-t_{i}\right)+1 / 2 \frac{\Delta \ddot{x}}{\Delta t}\left(t-t_{i}\right)^{2}
$$

and

$$
x(t)=x_{i}+\dot{x}_{j}\left(t-t_{i}\right)+1 / 2 \ddot{x}_{j}\left(t-t_{i}\right)^{2}+1 / 6 \frac{\Delta \ddot{x}_{i}}{\Delta t}\left(t-t_{i}\right)^{3}
$$

The evaluation of (87) and (88) at time $t=t_{j}+\Delta t$ gives

$$
\Delta \dot{x}_{i}=\ddot{x}_{j} \Delta t+1 / 2 \ddot{x}_{i} \Delta t
$$


and

$$
\Delta x_{i}=\dot{x}_{i} \Delta t+1 / 2 \ddot{x}_{j} \Delta t^{2}+1 / 6 \Delta \ddot{x}_{i} \Delta t^{2}
$$

where $\Delta x_{j}$ and $\Delta \dot{x}_{j}$ are defined in $(84)$ 。

Now it will be convenient to use the incremental displacement as the basic variable of the analysis. (89) is solved for the incremental acceleration $\Delta \ddot{x}_{i}$, and is substituted into equation (90) to obtain:

$$
\Delta \ddot{x}_{i}=\frac{6}{\Delta t^{2}} \Delta x_{i}-\frac{6}{\Delta t} \dot{x}_{i}-3 \ddot{x}_{i}
$$

and

$$
\Delta \dot{x}_{i}=\frac{3}{\Delta t} \Delta x_{i}-3 \dot{x}_{i}-\frac{\Delta t}{2} \ddot{x}_{i}
$$

Substituting (90) and (91) into equation (82)b leads to the following form of equation of motion:

$$
m_{\left\{\frac{6}{\Delta t}\right.} \Delta x_{i}-\frac{6}{\Delta t} \dot{x}_{i}-3 \ddot{x}_{i\}}+C_{i}\left\{\frac{3}{\Delta t} \Delta x_{i}-3 \dot{x}_{i}-\frac{\Delta t}{2} \ddot{x}_{i\}}+k_{i} \Delta x_{i}=\Delta F_{i}\right.
$$

Finally transferring all terms associated with containing the unknown incremental displacement $\Delta x_{j}$ to the left side gives,

$$
\bar{K}_{\mathbf{i}} \Delta x_{i}=\Delta \bar{F}_{i}
$$


in which

$$
K_{i}=K_{i}+\frac{6 m}{\Delta t^{2}}+\frac{3 C_{i}}{\Delta t}
$$

and

$$
\Delta \bar{F}_{i}=\Delta F_{i}+m\left\{\frac{6}{\Delta t} \dot{x}_{i}+3 \ddot{x}_{i}\right\}+c_{i}\left\{3 \dot{x}_{i}+\frac{\Delta t}{2} \ddot{x}_{i}\right\}
$$

It should be noted that (94) is equivalent to the static incremental-equilibrium equation, and may be solved for the incremental displacement by simply dividing the equivalent incremental load $\Delta F_{i}$ by the equivalent spring constant $\bar{K}_{i}$, that is,

$$
x_{i}=\frac{\overline{\Delta F}_{i}}{\bar{K}_{i}}
$$

To obtain the displacement at time $t_{i+1}=t_{j}+\Delta t$, this value of $\Delta x_{i}$ is substituted into (84)a yielding

$$
x_{i+1}=x_{i}+\Delta x_{i}
$$

Then the incremental velocity $\Delta \dot{x}_{i}$ is obtained from (92) and the velocity $t_{i+1}=t_{i}+\Delta t$ from $(84) b$ as

$$
\dot{x}_{i+1}=\dot{x}_{i}+\Delta \dot{x}_{i}
$$


Finally, the acceleration $\ddot{x}_{i+1}$ at the end of the time step is obtained directly from the differential equation of motion $(80) \mathrm{b}$ where the equation is written for time $t_{i+1}=t_{i}+\Delta t$. Hence from $(80) b$ it follows that

$$
\ddot{x}_{i+1}=\frac{1}{m}\left\{F\left(t_{i+1}\right)-c_{i+1} \dot{x}_{i+1}-k_{i+1} x_{i+1}\right\}
$$

After the displacement, velocity and acceleration have been determined at time $t_{i+1}=t_{i}+\Delta t$, the outlined procedure is repeated to calculate these quantities at the following time step $t_{i+2}=t_{i+1}+\Delta t$ and the process is continued to any desired final value of time.

This numerical procedure involves two significant approximations: 1L the acceleration is assumed to vary linearly during the time increment $\Delta t ;$ and 2) the damping and stiffness properties of the system are evaluated at the initiation of each time increment and assumed to remain constant during the time interval.

This concludes the background analysis of a single degree-offreedom system using step by step linear acceleration.' It was necessary to include this analys is in this chapter to present a modification of the extension of this method known as the Wilson- $\theta$ method, for the solution of the structures with elasto-plastic behavior.

The modification introduced by Wilson is utilized to assure the numerical stability of the solution process regardless of the magnitude selected for the time step; for this reason, such a method is said to be unconditionaliy stable. 
C. Incremental Equation of Motion

The basic assumption of the Wilson- $\theta$ method is that the acceleration varies linearly over the time interval from $t$ to $t+\theta \Delta t$ where $\theta \geq 1.0$. The value of the factor $\theta$ is determined to obtain optimum stability of the numerical process and accuracy of the solution. It has been shown by Wilson that, for $\theta \geq 1.38$, the method becomes unconditionaliy stable.

The equations expressing the incremental equilibrium conditions for a multidegree-of-freedom system can be derived as the matrix equivalent of the incremental equation of motion of the single degree-offreedom system (82)b. Thus taking the difference between dynamic equilibrium conditions defined at times $t_{j}$ and $t_{i+\tau}$, where $\tau=\theta \Delta t$; then the following incremental equations are obtained.

$$
\underset{\sim}{M} \hat{\Delta}_{\sim}^{\dot{x}}{ }_{i}+C(\dot{x}) \underset{\sim}{\Delta} \dot{x}_{j}+\underset{\sim}{K}(x) \underset{\Delta}{x_{i}}=\hat{\Delta} F_{i}
$$

in which the symbol over $\hat{\Delta}$ indicates that the increments are associated with the extended time step $\tau=\theta \Delta t$. Thus

$$
\begin{aligned}
& \hat{\Delta}_{\sim j}^{x}=\underset{\sim}{x}\left(t_{j}+\tau\right)-\underset{\sim}{x}\left(t_{j}\right), \\
& \hat{\Delta \hat{x}_{j}}=\underset{\sim}{\dot{x}}\left(t_{j}+\tau\right)-\underset{\dot{x}}{\dot{x}}\left(t_{j}\right), \\
& \hat{\Delta}_{\sim}^{\ddot{x}} j=\ddot{\sim}_{i}\left(t_{j}+\tau\right)-\ddot{x}_{\sim}\left(t_{j}\right) \text {, }
\end{aligned}
$$

and

$$
\hat{\Delta}{\underset{\sim}{i}}_{i}=\underset{\sim}{F}\left(t_{j}+\tau\right)-\underset{\sim}{F}\left(t_{j}\right)
$$


In writing (101), it was assumed that the stiffness and damping are obtained for each time step as the initial values of tangent of the corresponding curves, as shown in Figure 8, rather than the slope of the secant line which requires iteration. Hence the stiffness coefficient is defined as

$$
K_{i j}=\frac{d F_{s i}}{d x_{j}}
$$

and the damping coefficient as

$$
c_{i j}=\frac{d F_{D i}}{d x_{j}}
$$

in which $F_{S i}$ and $F_{D i}$ are respectively the elastic and damping forces at modal coordinate $i ; x_{j}$ and $\dot{x}_{j}$ are respectively the displacement and velocity at modal coordinate $j$.

D. The Wilson-e Method

At this point it is necessary to consider the detailed performance and efficiency of this unconditionally stable method of time integration, as it has al ready been mentioned, on the assumption that acceleration may be represented by a linear function during the time step $\tau=\theta \Delta t$ as is shown in Figure 10 。 


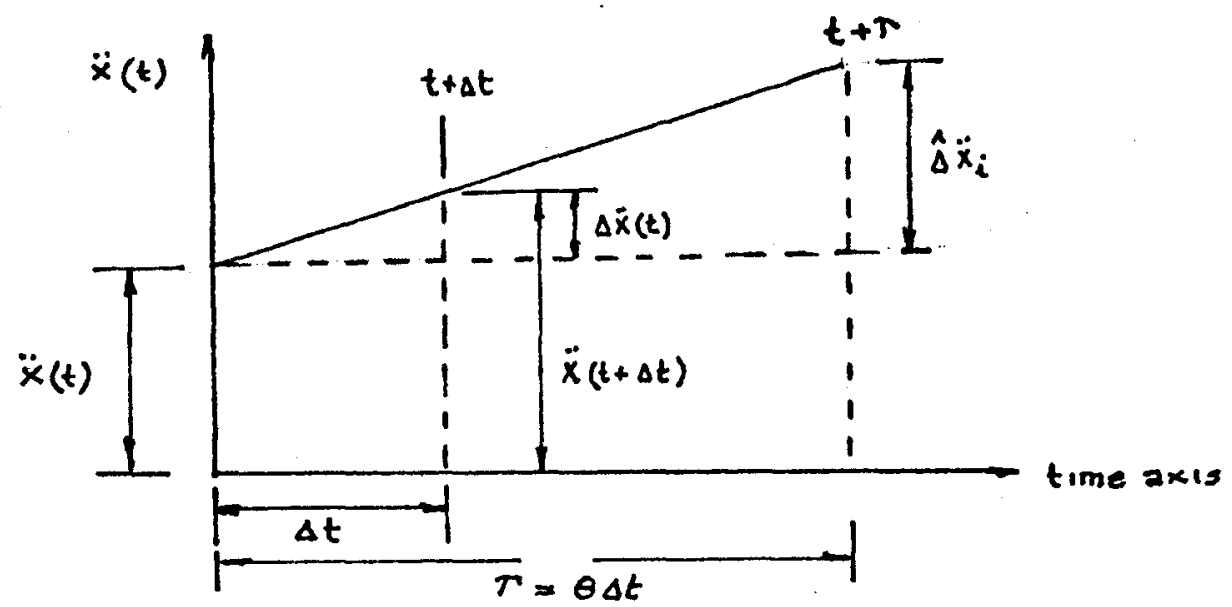

FIGURE 10 - Linear Acceleration; Normal and Extended Time Steps

From this figure can be written the linear expression for the acceleration during the extended time step as

$$
\underset{\sim}{\ddot{x}}(t)={\underset{\sim}{i}}_{i}+\frac{\hat{\Delta} \ddot{x}_{i}}{\tau}\left(t-t_{i}\right) \text {. }
$$

in which $\hat{\Delta} \ddot{x}_{i}$ is given by (102)c. Integrating (106) twice yields

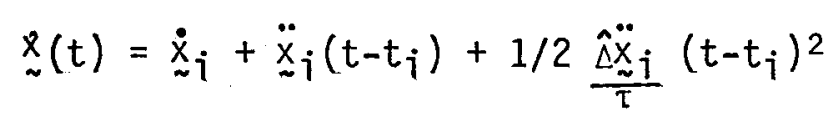

and

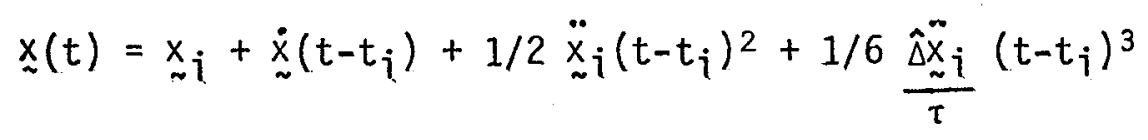

Evaluation of (107) and (108) at the end of the extended interval $t=t_{i}+\tau$ gives

$$
\hat{u}_{\sim}^{\dot{x}_{j}}=\ddot{x}_{i} \tau+1 / 2{\underset{\sim}{\hat{x}}}_{i} \tau
$$


and

$$
\hat{\Delta}_{\sim i}^{x} \tau+1 / 2{\underset{\sim}{\ddot{x}}}_{i} \tau^{2}+1 / 6 \hat{\Delta}_{\sim}^{\ddot{x}} \tau^{2}
$$

in which $\hat{\Delta}_{\tilde{i}}^{\mathrm{x}}$ and $\hat{\Delta}_{\underset{j}{\hat{\alpha}}}$ are defined by $(84) b, c$ respectively. Then (110) is solved for incremental acceleration $\hat{\Delta} \ddot{x}_{i}$ and substituted in (109) yields

$$
\hat{\Delta} \ddot{\sim}_{i}=\frac{6}{\tau^{2}} \hat{\Delta} x_{i}-\frac{6}{\tau}{\underset{\sim}{i}}_{i}-\underset{\sim}{3} \ddot{\sim}_{j}
$$

and

$$
\hat{\Delta} \underset{\sim}{\dot{x}_{i}}=\frac{3}{\tau} \underset{\sim}{\hat{\Delta} x_{i}}-3 \dot{x}_{i}=\frac{\tau}{2} \ddot{x}_{i}
$$

Finally, substituting (111) and (112) into the incremental equation of motion (82)b results in an equation for incremental displacement $\hat{\Delta}_{i j}^{x}$ which may be conveniently written as

$$
\bar{\sim}_{i} \hat{\Delta} x_{i}=\overline{\hat{\Delta} F_{i}}
$$

in which

$$
\bar{K}_{i}=\underset{\sim}{K_{i}}+\frac{6}{\tau^{2}} \underset{\sim}{M}+\frac{3}{\tau} \underset{\sim}{C_{j}}
$$

and

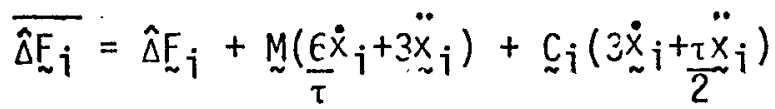


Equation (113) has the same form as the static incremental equilibrium equation and may be solved for the incremental displacement $\hat{\Delta}_{\sim}^{x} i$ by solving a system of linear equations.

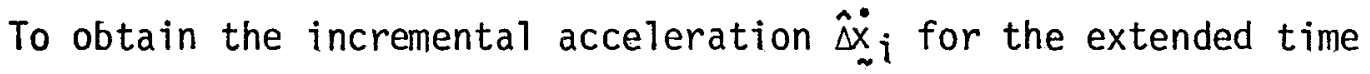
interval, the value of $\hat{\Delta}_{j}$ obtained from the solution of (113) is substituted into (111). The incremental acceleration $\hat{\Delta x}_{\sim}$ for the normal time interval $\Delta t$ is then obtained by a simple linear interpolation. Hence

$$
\ddot{\Delta x}=\frac{\ddot{\Delta x}}{\theta}
$$

To calculate the incremental velocity $\Delta_{\sim}^{\dot{x}_{j}}$ and incremental displacement $\Delta_{\sim j}^{x}$ and incremental displacement $\Delta_{\alpha}$ corresponding to the normal interval $\Delta t$, use is made of (109) and (110) with the extended time interval parameter $\tau$ substituted for $\Delta t$, that is

$$
\Delta \vec{x}_{i}=\ddot{\sim}_{i} \Delta t+1 / 2 \Delta \ddot{\sim}_{i} \Delta t
$$

and

$$
\Delta \underline{\sim}_{i}=\dot{x}_{i} \Delta t+1 / 2 \ddot{x}_{i} \Delta t^{2}+1 / 6 \Delta \ddot{x}_{i} \Delta t^{2}
$$

Finally, the displacement ${\underset{\sim}{j}+1}_{1}$ and velocity $\dot{x}_{i+1}$ at the end of the normal time interval are calculated by

$$
x_{\sim i+1}=x_{\sim i}+\Delta x_{\sim i}
$$


and

$$
\dot{\sim}_{i+1}=\dot{x}_{i}+\Delta \dot{x}_{i}
$$

As mentioned in the section dealing with single degree-of-freedom, the initial acceleration for the next step should be calculated from the condition of dynamic equilibrium at time $t+\Delta t$; thus

$$
\ddot{x}_{i+1}=\underline{\sim}^{-1}\left[\underline{\sim}_{i+1}-\underline{\sim}_{i+1} \stackrel{\dot{x}}{i+1}_{i}-\underline{\sim}_{j}+1 \stackrel{\sim}{x}_{i+1}\right]
$$

in which the products ${\underset{\sim}{j}+1}_{i+1}^{x_{j}}$ and $\underset{\sim}{K_{j+1}}{\underset{\sim}{x}}_{i+1}$ represent respectively the damping force and the stiffness force vectors evaluated at the end of the time step $t_{i+1}=t_{i+\Delta t}$. Once the displacement, velocity and acceleration vectors at time $t_{i+1}=t_{i+\Delta t}$, then the out 7 ine procedure is repeated to calculate these quantities at the next step $t_{i+2}=t_{i+1}+\Delta t$ and the process is continued until the desired final time.

E. Algorithm for Step-by-Step Solution of a Linear System, Using the Wilson- $\theta$ Integration Method

Initiation of Values:

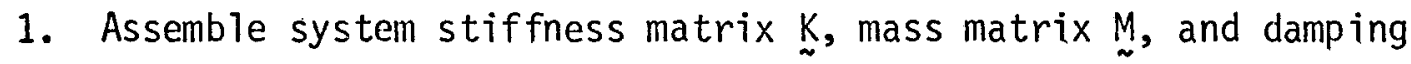
matrix $\underset{\sim}{C}$.

2. Set initial values for displacement ${\underset{\sim}{x}}_{0}$, velocity ${\underset{\sim}{0}}_{0}$ and forces $E_{0^{\circ}}$

3. Calculate initial acceleration $\ddot{\sim}_{0}$ from

$$
\underset{\sim}{M} \ddot{x}_{0}=F_{0}-\underset{\sim}{C} \underset{\sim}{\dot{x}_{0}}-\underset{\sim}{K} x_{\sim}
$$


4. Select time step $\Delta t$, the factor $\theta$ (for all practical purposes taken as 1.4) and calculate the constants, $\tau, a_{1}, a_{2}, a_{3}$ and $a_{4}$ for the following relation

$$
\tau=\theta \Delta t ; a_{1}=\frac{3}{\tau}, a_{2}=\frac{6}{\tau}, a_{3}=\frac{\tau}{3}, a_{4}=\frac{6}{\tau^{2}}
$$

5. From the effective stiffness matrix $\underset{\sim}{\bar{K}}$, namely

$$
\underset{\sim}{K}=\underset{\sim}{K}+a_{4} \underset{\sim}{M}+a_{1} \underset{\sim}{C}
$$

For Time Intervals (one at the time):

1. Calculate by linear interpolation the incremental load $\hat{\Delta} \mathrm{E}_{i}$ for the time interval $t_{j}$ to $t_{j}+\tau$, from the relation

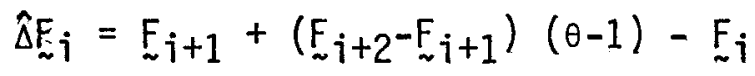

2. Calculate the effective incremental load $\overline{\hat{\Delta} F_{i}}$ for the time interval $t_{i}$ to $t_{i+\tau}$, from the relation

$$
\overline{\hat{\Delta}} F_{\sim}=\hat{\Delta} F_{i}+\left(a_{2} M+3 C\right) \dot{\sim}_{\sim}+\left(3 M_{\sim}+a_{3} C\right) \ddot{\sim}_{i}
$$

3. Solve for incremental displacement $\hat{\Delta x}_{i}$ from

$$
\mathbb{K}_{\sim} \hat{\Delta} x_{i}=\overline{\hat{\Delta} F_{i}}
$$

4. Calculate the incremental acceleration for the extended time interval $\tau$, from the relation 


$$
\hat{\Delta} \ddot{\sim}_{i}=\frac{6}{\tau^{2}} \hat{\Delta}{\underset{\sim}{x}}_{i}-\frac{6}{\tau} \dot{x}_{i}-3 \cdot \ddot{x}_{i}
$$

5. Calculate the incremental acceleration for the nomal interval from

$$
\Delta \ddot{x}=\frac{\hat{\Delta} \ddot{x}}{\theta}
$$

6. Calculate the incremental velocity $\Delta_{\sim}^{\hat{x}}$ and the incremental displacement $\Delta \underline{\sim}_{i}$ from time $t_{j}$ to $t_{j}+\Delta t$ from the following relations

$$
\begin{gathered}
\Delta{\underset{\sim}{\dot{x}}}_{i}=\ddot{\sim}_{j} \Delta t+1 / 2 \Delta \ddot{\sim}_{i} \Delta t \\
\Delta \ddot{\sim}_{i}={\underset{\sim}{\dot{x}}}_{j} \Delta t+1 / 2{\underset{\sim}{\tilde{x}}}_{j} \Delta t^{2}+1 / 6 \ddot{\sim}_{i} \Delta t
\end{gathered}
$$

7. Calculate the displacement and velocity at time $t_{i+1}=t_{j}+\Delta t$ using

$$
\begin{aligned}
& \Delta{\underset{\sim}{i+1}}_{i+1}={\underset{\sim}{i}}_{i}+\Delta \underline{\sim}_{i} \\
& \Delta \dot{x}_{i+1}={\underset{\sim}{\dot{x}}}_{i}+\Delta \dot{x}_{i}
\end{aligned}
$$

8. Calculate the acceleration $\ddot{x}_{i+1}$ at time $t_{i+1}=t_{i}+\Delta t$ directly from the equilibrium equation of motion, namely

$$
M \ddot{x}_{i+1}=E_{i+1}-\mathfrak{\sim}{\underset{\sim}{\sim}}_{i+1}-\underset{\sim}{\operatorname{K}} \underset{i+1}{ }
$$




\section{F. Subroutine Step}

This is used for a type of dynamic loading of irregular behavior such as an earthquake. This subroutine will find the response for each modal coordinate at each increment of time up to the maximum specified by programer. The list of operational variables are shown in a tabular form, below.

\begin{tabular}{|c|c|c|}
\hline Variable & Symbol in Thes is & Description \\
\hline $\operatorname{SK}(I, J)$ & {$[\mathrm{K}]$} & System stiffness matrix \\
\hline $\operatorname{SM}(I, J)$ & {$[M]$} & System mass matrix \\
\hline $\operatorname{SC}(I, J)$ & {$[C]$} & System damping matrix \\
\hline ND & N & Number of degrees-of-freedom \\
\hline THETA & $\theta$ & Wilson- $\theta$ factor \\
\hline DT & $\Delta t$ & Time step of integration \\
\hline TMAX & & Maximum time of integration \\
\hline $\operatorname{NEQ}(L)$ & & $\begin{array}{l}\text { Number of data points for } \\
\text { excitation at modal coordinates } \\
(L-1, N D)\end{array}$ \\
\hline$T C(I), P(I)$ & $t_{i}, F_{i}(t)$ & Time-force values \\
\hline
\end{tabular}

G. Program 4 - Seismic Response of Shear Buildings

A computer program for the analysis of a multidegree-of-freedom shear building with elastoplastic behavior, linear viscous damping, subjected to an arbitrary acceleration at the foundation, is presented in this section. This program may be conceived as a combination of three computer programs already presented: (1) the elastoplastic single degree-of-freedom system; (2) the seismic response of elastic shear buildings using modal superposition method; and (3) the subroutine 
STEP using the Wilson- $\theta$ integration method for linear systems in this chapter.

The listing of Program 4 is given on page 89. The program calls subroutine JACOBI to solve the eigenproblem of the system in the linear range and then calls subroutine DAMP to determine from specified modal damping ratios, the damping matrix of the system. A listing of the principal variables used in the program are given below. Input data cards and corresponding formats are indicated following the list of variables. 


\begin{tabular}{|c|c|c|}
\hline Variables & Symbots in Thes is & Description \\
\hline SK $(I, J)$ & {$[K]$} & Stiffness matrix \\
\hline $\operatorname{SM}(I, J)$ & [M] & Mass matrix \\
\hline SC $(I, J)$ & {$[\mathrm{C}]$} & Damping matrix \\
\hline THETA & $\theta$. & Wilson- $\theta$ factor \\
\hline DT & $\Delta t$ & Time step \\
\hline E & $E$ & Modules of elasticity \\
\hline GR & g & Acceleration of gravity \\
\hline TMAX & & Maximum time of calculation \\
\hline NEQ & NT & $\begin{array}{l}\text { Number of data points for the } \\
\text { excitation }\end{array}$ \\
\hline ND & N & Number of degrees-of-freedom \\
\hline IFPR & & $\begin{array}{l}\text { Printing index of subroutine } \\
\text { JACOBI: } 1=\text { Print eigenvalues } \\
\text { during iteration; } 0=\text { Do not } \\
\text { print }\end{array}$ \\
\hline SI & I & $\begin{array}{l}\text { Moment of inertia of story } \\
\text { columns }\end{array}$ \\
\hline SL & $L$ & Height of story \\
\hline SM $(I, I)$ & M & Mass at floor level \\
\hline PM & $M_{p}$ & Plastic moment of story \\
\hline$T C(I), P(I)$ & $t_{i}, F_{i}$ & $\begin{array}{l}\text { Time-Acceleration values } \\
\text { (acceleration in } g^{\prime} s \text { ) }\end{array}$ \\
\hline XIS (I) & $\xi_{i}$ & Modal damping ratios \\
\hline
\end{tabular}

\begin{tabular}{|c|c|}
\hline Formats & Variables \\
\hline$(2 F 10.2,3 F 10,0,3 I 5)$ & THETA \\
\hline$(8 F 10.0)$ & PM (one card per degree of \\
\hline$(8 \mathrm{~F} 10.2)$ & $P(L) \quad(L=1, N E Q)$ \\
\hline$(8 F 10.3)$ & $(L=1, N D)$ \\
\hline
\end{tabular}


H. Illustrative Example

Use Program 4 to detemine the response of the two-story shearbuilding of the example subjected to a constant acceleration of $0.28 \mathrm{~g}$ applied suddenly at the foundation. The plastic moment for the columns on the first or second story is $M_{p}=15,0001 \mathrm{~b}$-in.

The listing of the input data followed by the computer results are shown on the following page. 
$=\quad \because$ Input Data and Computer Results

Input Data

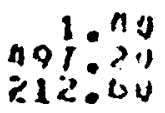

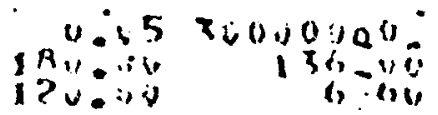

380.

Tรuvi:

1.

2

2

\section{EIRENVAI,!CS}

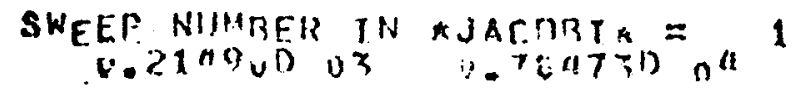

SHEEP NHARER JN JACOLTE $=$ ?

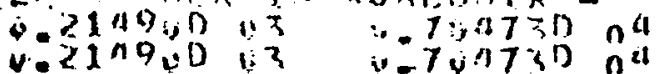

ETRFNUFCIURS

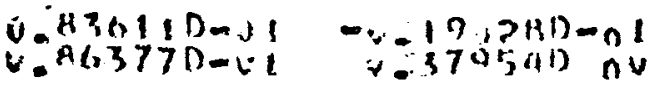

THE. DAMPING MATRIX IS

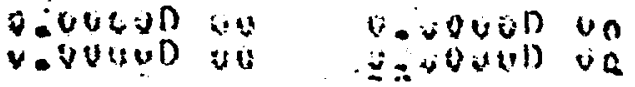

THE RESPIHSF IS

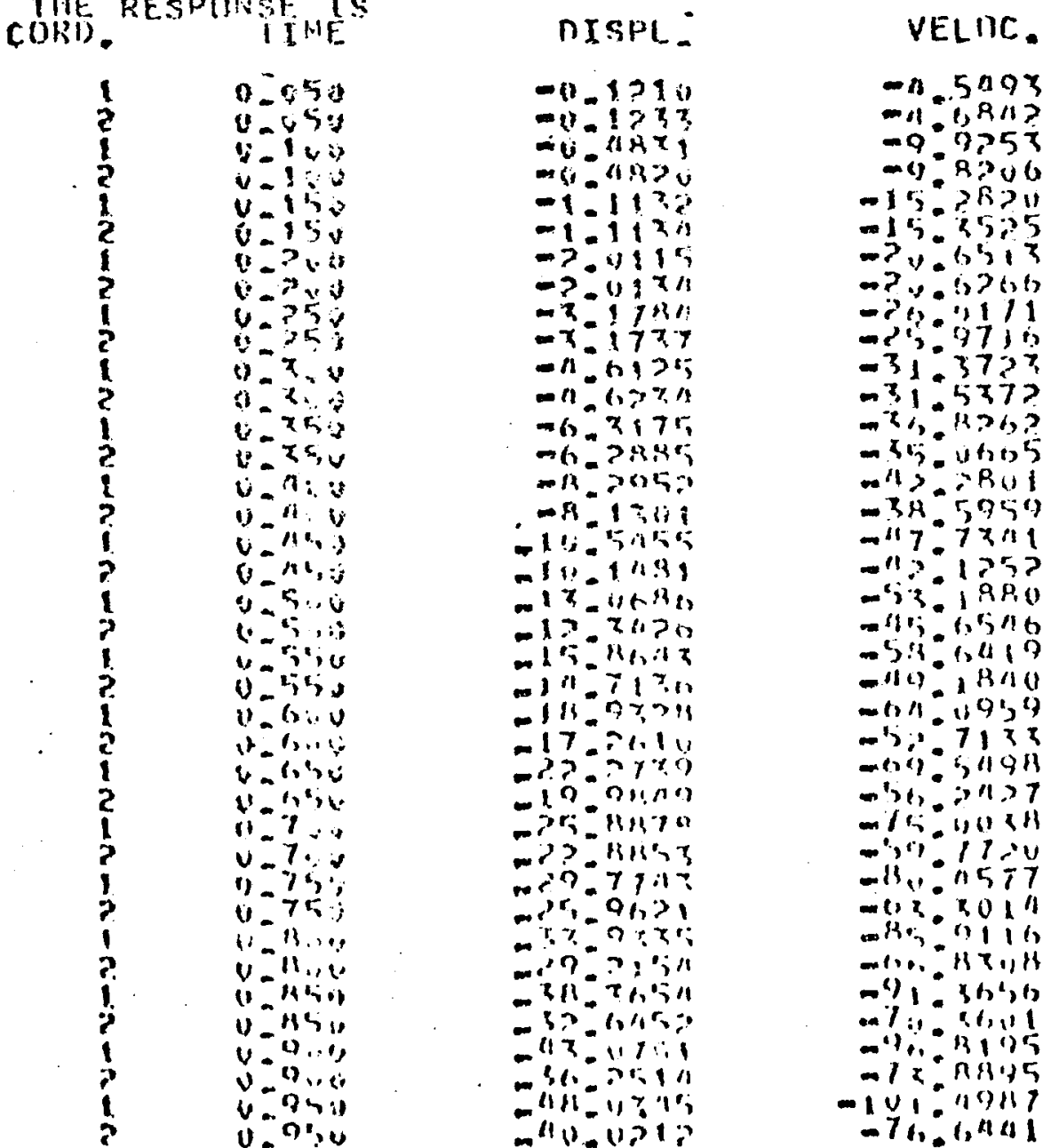

ACr.

$-117.9 \% 35$

$-93: 3823$

-106:8983

$-115.7231$

$-117: 357$

$-100.5670$

- $1,1, B, R R$ $-95.72115$

$-115: 6008$

$-1119.2713$

$-119.4787$

$-7 \% .527 ?$

$-109.07137$

$-74.5 R 7$ ?

$-1119: 1787$

$-71.5117 ?$

$-1119=075 \% ?$

$-70.547 \%$

$-109: 11787$

-70.547 ?

$-1119: 11787$

$-71.5 K 7$ ?

$-109.11787$

$-74.5137 ?$

- 1040787

$-70: 5377$ ?

$-100=11781$

$-70: 587 \%$

$-109: 17 \pi 7$

-711.9477 ?

$-1,1101187$

$-71, \div 417$

$-141.47 \pi 1$

$-711: 187$ ?

$-1119.11187$

$-711.597 ?$

-1109.118 ?

$-70.51172$ 
I. Program Listing

SJOB
C
$C$
$C$

SEISMIC RESPCNSE ELASTOPLASTIC SHEAR BUILDING

IMPLICIT REAL*Q(A-H,O-Z)

DIMENSICN SK(30,30),SM(30,30),SC(30,30),F(30),X(30,30),CD(30),

1 DUA $(30), U D(30), U V(30), U A(30), T C(30), P(30), S K P(30), F T(30)$,

$1 R(30), Y T(30), Y C(30), S(30), S P(30), K E Y(30), E I G E A:\{30)$

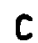

C

C

\section{READ INPUT DATA AND INITIALIZE}

READ(5,100) THETA,DT,E,GR,TMAX,NEQ,ND,IFPR

HRITE (E, IOO) THETA, DT,E, GR, TMAX, NEQ, ND, IFPR

100 FORMAT $(2 F 10.2,3 F 10.0,3$ IS)

$N X=T M A X / D T+2$

DO $1 \quad I=I, N X$

$1 F(I)=0.0$

$D O 2 I=1, N D$

$D O 2 J=1, N D$

$\operatorname{SM}(I, J)=0.0$

$\operatorname{SC}(I, J)=0.0$

$X(I, J)=0.0$

$2 \operatorname{SK}(I, U)=0.0$

ND1 $=N D+1$

$T U=T H E T A \star D T$

$A 1=3 . / T U$

$A 2=6 . / T U$

$A 3=T U / 2$.

$A 4=A 2 / T U$

DO $7 I=1, N D$

READ $(5,110) S I, S L, S M(I, I), P M$

WRITE $(E, 110) S I, S L, S M(I, I), P M$

110 FORMAT $(3 F 10.2, F 10.0)$

$S(I)=12.0 * E * S I / S L \star * 3$

$S P(I)=S(I)$

$R T(I)=2 \star P M / S L$

$S C(I, I)=S M(I, I)$

$U D(I)=0.0$

$U V(I)=0.0$

$Y T(I)=R T(I) / S(I)$

$Y C(I)=-R T(I) / S(I)$

$\operatorname{KEY}(I)=0$

$7 S P(I)=S(I)$

C

c

C

ASSEMBLE STIFFNESS MATRIX

$S(N D+1)=0 \cdot 0$

DO $1 \% I=1, N D$

IF (I.EQ.1) GO TO 19

$S K(I, I-1)=-S(I)$

$S K(I-1, I)=-S(I)$

19. $S K(I, I)=S(I)+S(I+1)$

C

DETERMIPE NATUPAL FREQUENCIES AND MOOE SHAPES

C

CALL JACOEI (SK,SC,X,EIGEN,TC,ND,IFPR)

C

DETERMINE DAMPING MATRIX

C

CALL DAMP (NO, X,SM, SC,EIGEN)

RTAO(5.120) (TC(1),P(1).1 =1. NFO) 
WRITE $(6,12 C)(T C(L), P(L), L=1, N E Q)$

C 120 FORMAT $(4 F 10.2)$

DO $4 I=1, N E Q$

$4 P(I)=P(I) \star G R$

INTERPOLATION PETWEEN DATA POINTS

C

$N T=T C(N E Q) / D T$

$N T 1=N T+1$

$F(1)=P(1)$

$A N N=0.0$

II $=1$

DO $10 \quad I=2, N T 1$,

$A I=I-1$

$T=A I * D T$

IF (T.GT.TC(NEQ)) GO TO 16

IF $(T \cdot L E \cdot T C(I I+1))$ GO TO 9

$A N N=-T C(I I+I)+T-D T$

$I I=I I+1$

$9 \quad A N N=A N N+D T$

$F(I)=P(I I)+(P(I I+1)-P(I I)) * A N N /(T C(I I+1)-T C(I I))$

C

10 CONTINUE

16 CONTINUE

C

INITIALIZE AND DETERMINE INITIAL ACCELERATION

C

C

$N T=T M A \times / D T$

DD $22 I=1, N D$

$X(I, N D 1)=-F(1) \star S M(I, I)$

DO $22 \mathrm{~J}=1, \mathrm{ND}$

$22 X(I, J)=S M(I, J)$

CALL SDLVE $(N D, X)$

DO $23 \quad I=1$, ND

$23 U A(I)=X(I, N D I)$

$S P(N D+1)=0.0$

$R(N D+1)=0.0$

C

LOOP OVER TIME CALCULATING RESPONSE

WRITE $(6,170)$

DO $\subseteq 0 \mathrm{~L}=1$, NT

$A L=L$

$T=D T * A L$

DO $20 \quad I=1$, ND

IF (I.EQ.1) GO TO 20

$S K(I, I-1)=-S P(I)$

$S K((I-I), I)=-S P(I)$

$20 S K(I, I)=S P(I)+S P(I+1)$

DO $2.5 \quad 1=1, N 0$

DO $25 \mathrm{~J}=1 \cdot N D$

$25 X(I, J)=S K(I, J)+A 4 * S M(I, J)+A 1 * S C(I, J)$

DC $35 I=1, N D$

$x(I, N D I)=(F(L+1)+(F(L+2)-F(L+1)) *(T H E T A-1.0)-F(L)) \star(-S M(I, I))$ $0030 \quad J=1,: 0$

$30 x(I, N D 1)=X(I, N O 1)+(S M(I, J) * A 2+S C(I, J) * 3,0) * U V(J)$

$1+(S M(I, J) * 3.0+A, \pi \operatorname{SC}(I, J)) \star U A(J)$

35 CONTINUF.

CALL SOLVE (ND, X)

DO $38 \quad I=1, N 0$

$\operatorname{DUA}(I)=A 4 * X(I, N J 1)-A 2 * U V(I)-3.0 * U A(I)$

DUA $(I)=D U A(I) / T H E T A$ 
DUV =DT*UA (I) +OT*DUA (I) $/ 2.0$

$U D(I)=U D(I)+D T \star U V(I)+D T \star D T \star U A(I) / 2 \bullet O+D T \star D T \star D U A(I) / 6.0$

$39 \quad U V(I)=U V(I)+D U V$

$D O(1)=U D(1)$

$D O 39 \quad I=2,100$

$39 D D(I)=U D(I)-U D(I-1)$

DO $40 \quad I=1$, NO

IF (KEY(I)) $11,12,13$

$12 R(I)=R T(I)-(Y T(I)-D O(I)) \star S(I)$

$S P(I)=S(I)$

IF (DD(I).GT.YC(I).AND.DD(I).LT.YT(I)) GO TO 40

IF (DD(I).LT.YC(I)) GO TO 15

$\operatorname{KE} Y(I)=1$

$S P(I)=0.0$

$R(I)=R T(I)$

GO TO 40

13 IF (UV(I).GT.0.) GC TO 40

$\operatorname{KEY}(I)=0$

$S P(I)=S(I)$

$Y T(I)=D D(I)$

$Y C(I)=D D(I)-2 \cdot 0 * R T(I) / S(I)$

$R(I)=R T(I)-(Y T(I)-D D(I)) * S(I)$

60 TO 40

11 IF (UV(I).LT.O) GO TO 40

$\operatorname{KEY}(I)=0$

$S P(I)=S(I)$

$Y C(I)=D D(I)$

$Y T(I)=D O(I)+2 * R T(I) / S(T)$

$R(I)=R T(I)-(Y T(I)-D D(I)) \star S(I)$

GO TO 40

$15 K E Y(I)=-1$

$R(I)=-R T(I)$

$S P(I)=0.0$

40 CONTTNUE

DO $50 \quad I=1, N D$

$X(I, N D I)=F(L+I) *(-S M(I, I))-R(I)+R(I+I)$

$D O 45 \mathrm{~J}=1,1 \mathrm{D}$

$X(I, N D 1)=X(I, N D 1)-S C(I, U) \star U V(J)$

$45 X(I, J)=\operatorname{SM}(I, J)$

50. CONTINUE

CALL SOLVE $(N D, X)$

DC $60 \quad I=1, N D$

$U A(I)=X(I \cdot N D 1)$

60 WRITE $(E, 250)$ I, T,UD(I),UV(I),UA(I)

90 CONTINUE

170 FORMAT (1H1,5X, PTHE RESPONSE IS•,/,5X, 'CORD.・,6X, *TIME*,9X, 1 DISPL., $9 X$, VELCC. $, 11 X, \cdot A C C . \bullet /)$

250 FORMAT $(110, F 10,3,3 F 15.4)$

STOP

END

SUBROUTINE SOLVE $(N, A)$

IMPLICIT REAL * $9(A-H, O-Z)$

DIMENSION $\quad(30,30)$

$M=1$

$E P S=1 \cdot 0 E-10$

$N^{2} L U S H=N+M$

$D E T=1 \cdot 0$

DC $9 K=1, N$

$D E T=D E T * A(K, K)$

IF $(D A B S(A(K, K)), G T \cdot E P S)$ GO TO 5 
C

c

C

c

c

c

C

$5 K P 1=K+1$

DO $6 J=K P 1, \quad N P L U S M$

$6 \quad A(K, J)=A(K, J) / A(K, K)$

$A(K, K)=1$.

DO $9 I=1, N$

IF $(I, E Q \cdot K \cdot O R \cdot A(I, K), E Q .0$.$) SO TO. 9$

DO 8 J $=K P 1, N D L U S M$

$8 A(I, U)=A(I, U)-A(I, K) \star A(K, J)$

$A(I, K)=0.000$

9 CONTINUE

202 FORMAT(Z7HOSMALL PIVOT -MATRIX MAY BE SINGULAR)

99 RETURN

END

SUBRCUTINE JACCBI (A,B,X,EIGV,D,N,IFPR)

IMPLICIT REAL $*(A-H, O-Z)$

DIMENSION $A(30,30), B(30,30), \times(30,30), E I G V(30), D(30)$

INITIALIZE EIGENVALUE AND EIGENVECTOR MATRICES

WRITE $(6,1990)$

NSMAX $=15$

RTCL $=1 \cdot D-12$

IOUT $=6$

DO $10 \quad I=1, N$

IF (ACI,I ).GT.0. .AND. B(I,I).GT.0.) GO TO 4

WRITE(IOUT, 202C)

STOP

$4 D(I)=A(I, I) / B(I, I)$

10 EIGV(I) $=D(I)$

$0030 \quad I=1, N$

DO $20 \mathrm{~J}=1, \mathrm{~N}$

$20 \times(I, J)=0$.

$30 \times(I, I)=1$.

IF (N.50.1) RETURN

INITIALIZE SWEEP COUNTER AND EEGIN ITERATION

NSHEED $=0$

$N R=N-1$

40 NSHEEP $=$ NSWEEP +1

IF (IFPR.EQ.1)HFITE(IOUT, 2000$)$ NSWEEP

CHECK IF PRESENT OFF-DIAGONAL ELEMENT IS LARGE

EPS $=(.01 \star \star N S W E E P) \star \star 2$

DO $210 \mathrm{~J}=1$, NR

$J U=J+1$

DC $210 K=J U, N$

EPTOLA $=(A(J, K) \star A(J, K)) /(A(J, J) * A(K, K))$

EPTCLB $=(B(U, K) * B(J, K)) /(B(J, J) * B(K, K))$

IF ( (EPTOLA.LT.EPS) A AND. (EPTOLB.LT.EPS)) GO TO 210

$A K K=A(K, K) \times R(J, K)-B(K, K) * A(J, K)$

$A J J=A(J, J) * B(J, K)-E(J, J) * A(J, K)$

$A B=A(J, J) * F(K, K)-A(K, K) * F(J, J)$

$C H E C K=(A B * A E+4 * * A K K * A J J) / 4$. 
50 HRITE (ICUT, 2020$)$

STDP

60 SQCH DSSRT (CHECK)

$D_{1}=A B / 2 \cdot+3 A C H$.

$D 2=A B / 2 \cdot-5 O C H$

$D E N=D 1$

IF (DABS (D2) . GT - DABS (D1)) DEN $=02$

IF $(D E N) \& 0,70,80$

$70 \quad C A=0$.

$C G=-A(J, K) / A(K, K)$

$C G=-A(J, K) / A(K, K)$

GO TO 90

$80 C A=A K K / D E N$

$C G=-A J J / D E N$

90 IF $(N-2) 100,190,100$

$100 \quad J P 1=J+1$

$J M 1=J-1$

$K P 1=K+1$

$K M 1=K-1$

IF $(J M 1-1) 130,110,110$

110 DO $120 \quad I=1, J M 1$

$A J=\Delta(I, J)$

$B J=B(I, J)$

$A K=A(I, K)$

$B K=B(I, K)$

$A(I, U)=A J+C G \star A K$

$B(I, J)=B J+C G \star B K$

$A(I, K)=A K+C A \star A J$

$120 B(I, K)=B K+C A \star B J$

130 IF $(K P 1-N) 140,140,160$

140 DO $150 \quad I=K P 1, N$

$A J=A(U, I)$

$B J=B(U, I)$

$A K=A(K, I)$

$B K=B(K, I)$

$A(J, I)=A J+C G \star A K$

$B(J, I)=E J+C G \star B K$

$A(K, I)=A K+C A * A J$

$150 \mathrm{~B}(K, I)=B K+C A \star B J$

$160 \quad I=(J P 1-K M 1) 170,170,190$

170 OO 1 SO I=JP $1, K M 1$

$A J=A(J, I)$

$B J=B(J, I)$

$A K=A(I, K)$

$B K=B(I, K)$

$A(J, I)=A J+C G * A K$

$B(J, I)=P J+C G \star B K$

$A(I, K)=A K+C A \star A J$

$180 \quad B(I, K)=B K+C A * B J$

$190 \quad A K=A(K, K)$

$B K=B(K, K)$

$A(K, K)=A K+2 * C A \star A(J, K)+C A \star C A \star A(J, J)$

$B(K, K)=E K+2 * A A * B(J, K)+C A * C A * B(J, J)$

$A(J, J)=A(J, J)+2 *(G * A(J, K)+C G * C G \star A K$

$B(J, J)=B(J, J)+2 * C G \star B(J, K)+C G \star C G \star B K$

$A(J, K)=0$.

$B(J, K)=0$. 
c

C

C

UPDATE THE EIGENVECTOR MATRIX AFTER EACH ROTATION

C

C

c

C

230 OD $240 \quad I=1, N$

$T O L=R T C L \star D(I)$

$D I F=D A B S(E: G V(I)-D(I))$

IF (DIF.GT.TOL)GO TO 280

240 CONTINUE

C

c

C

c 250 CONTINUE

CHECK ALL CFF-DIAGCNAL ELEMENTS TO SEE IF ANCTHER SWEED I REQUIRED

EPS $=R T C L \star \star 2$

DO $250 \mathrm{~J}=1, \mathrm{NR}$

$J J=J+1$

DO $250 \quad K=J U, N$

EPSA $=(A(J, K) * A(J, K)) /(A(J, J) * A(K, K))$

$E P S B=(B(J, K) * B(J, K)) /(E(J, J) * B(K, K))$

IF (EPSA.LT.EPS).ANO. (EPSB.LT.EPS)) GO TO 250 GO TO 280

C FILL OUT BCTTOM TRIANGLE OF RESULTANT MATRICES

C AND SCALE EIGENVECTORS

C

255 DO $260 \quad I=1, N$

$00260 \mathrm{~J}=1$, in

$A(J, I)=A(I, J)$

$260 B(J, I)=E(I, J)$

$D O \quad 270 \quad J=1, N$

$B B=D S Q R T(E(J, J))$

DO $270 \quad K=1$, N

$270 x(k, J)=x(k, J) / B B$

UPDATE MATRIX AND START NEW SWEEP, IF ALLCWED

URITE $(6,2010)$ (EIGV(IL),IL $=1, N)$

WRITE $(6,1990)$

DO $1991 \quad L:=1$, i

1951 WRITE $(6,2010)(X(L I, L J), L J=1, N)$

1990 FORMAT (//,10X, 'EIGENVALUFS, /)

1990 FORMAT (/10X, EIGENVECTORS , / $)$ 


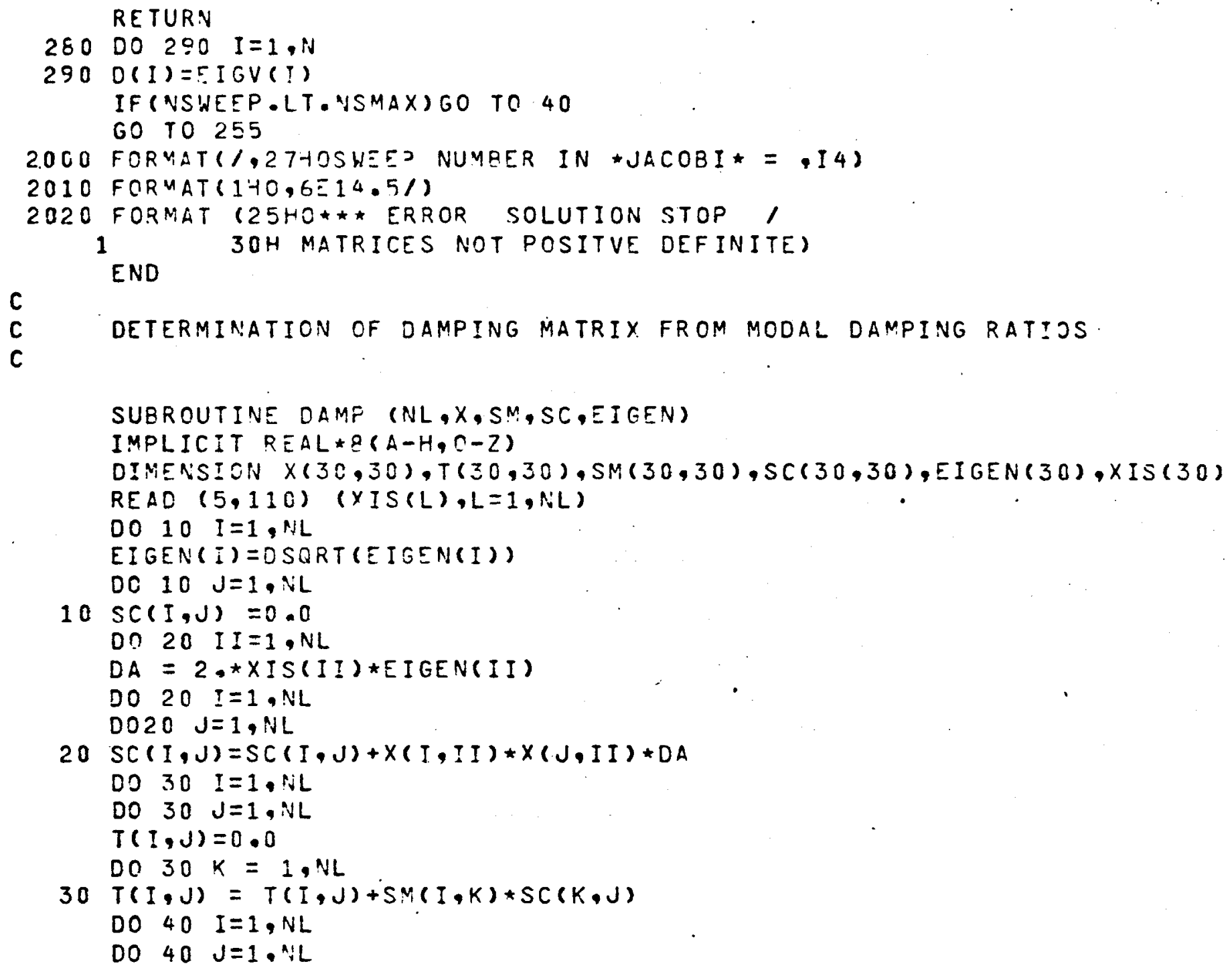


330

331

332

333

334

335

336

337

338

339

340
$S C(I, J)=0.0$

DO $40 \mathrm{~K}=1, \mathrm{NL}$

$40 S C(I, J)=S C(I, J)+T(I, K) * S M(K, J)$

HRITF $(6,170)$

170 FORMAT $(/ /, 5 X$, THE DAMPING MATRIX IS,$/)$ DO $50 \quad I=1, N L$

50 WRITE $(6,120) \quad(S C(I, J), J=1, N L)$

110 FORMAT (3F10.2)

120 FORMAT (GD14.4)

RETURN

END

\section{SENTRY}

$\begin{array}{rrrrrrrr}1.40 & 0.05 & 30000000 & 386 & 1 . & 2 & 2 & 1 \\ 497.20 & 180.00 & 136.00 & 1000000 . & & & \end{array}$

\section{EIGENVALUES}

WEEP NUMEER IN * JACOBI* $=1$

0.139900 a3 $0.105250 \quad 04$

WEEP NUMBER IN * JACOBI* $=2$

$0.13990003 \quad 0.10325004$

$0.13990003 \quad 0.105250 \quad 04$

EIGENVECTORS

$0.643700-01-0.566520-01$

$0.813230-01 \quad 0.924020-01$

THE DAMPING MATRIX IS

$\begin{array}{ccccc}0.00000 & 00 & 0.00000 & 00 & \\ 0.0000000 & 0.00000 & 00 & \\ 0.00 & 0.28 & 1.00 & 0.28\end{array}$


THE RESPONSE IS CORD. TIME

DISPL.

$-0.1224$

$-0.1309$

$-0.4352$

$-0.4900$

$-0.8773$

$-1.0216$

$-1.4830$

$-1.6151$

$-2.2483$

$-2.2896$

$-3.1272$

$-3.1373$

$-4.1031$

$-4.1951$

$-5.2166$

$-5.3785$

$-5.5039$

$-6.6126$

$-7.9395$

$-7.9504$

$-9.4735$

$-9.4943$

$-11.1095$

$-11.2372$

$-12.9011$

$-13.0654$

$-14.8698$

$-14.0437$

$-16.9694$

$-16.9564$

$-19.1560$

$-19.2030$

$-21.4573$

$-21.6202$

$-23.9323$

$-24.0886$

$-26.5665$

$-26.5995$
VELOC.

ACC.

$-83.6079$

$-102.7505$

$-46.8792$

$-67.0241$

$-73.7455$

$-11.6610$

$-69.5076$

$-19.7756$

$-39.8756$

$-81.4515$

$-30.0255$

$-101.7425$

$-56.7322$

$-46.7187$

$-79.4874$

0.1706

$-62.1527$

$-35.4 E 75$

$-30.3152$

$-101.1532$

$-33.5414$

$-94.5050$

$-68.3586$

$-22.7407$

$-81.2444$

$3.7 \$ 11$

$-50.8350$

$-58.8705$

$-23.1836$

$-115.8433$

$-42.0776$

$-76.9121$

$-79.8093$

0.8340

$-77.65+3$

$-3.5055$

$-37.1571$

$-66.5729$ 


\section{BIBLIOGRAPHY}

Brebbia, C. A。, Vibrations of Engineering Structures (Kentucky: Computational Mechanics, Ltd, 1976), p。 105.

Clough, R. Wo and Penzien, J., Dynamics of Structures (New York: McGrawHi11, 1975), pp. 118, 260 .

James, M. L., Smith, G. M. and Wolford, J. Co, Applied Numerical Methods for Digital Computation with Fotran (Pennsylvania: International Textbook Company, 1967), p. 433.

Paz, M., Structural Dynamics (New York: Van Nostrand Reinhold, 1979), pp. 19-6 and 19-7. 


\section{VITA}

The author, Jose Enrique Carrasco, was born in La Paz, Bolivia on March 20,1950。 He is the son of Mario Carrasco Gumucio, Hydraulic Engineer and the late Victoria Valdivieso Guzman de Carrasco, Kindergarden Principal. He graduated from Israeli High School in La Paz, Bolivia in May, 1968. The same year he enrolled in the University "Tomas Frias" in Potosi, Bolivia. In 1973 he transferred to the University of Louisville, where he received the Bachelor of Science in May 1977. He was a project manager for a construction company in Sellersburg, Indiana and then in 1978 he completed his Master of Engineering with specialty in Civil Engineering (Structural Dynamics)。 He is married to the former Gayle Jo Senger from Devils Lake, North Dakota。 They have a daughter named Alexandra Victoria born on October 25, 1978。 